\title{
Gastric Ulcer Healing Property of Bryophyllum pinnatum Leaf Extract in Chronic Model In Vivo and Gastroprotective Activity of Its Major Flavonoid
}

OPEN ACCESS

Edited by:

Mahendra Rai,

Sant Gadge Baba Amravati University,

India

Reviewed by:

Simona Gabriela Bungau, University of Oradea, Romania

Ahmad Salahuddin,

Damanhour University, Egypt

*Correspondence: Silvana Maria Zucolotto szucolotto@hotmail.com

Specialty section: This article was submitted to Inflammation Pharmacology,

a section of the journal

Frontiers in Pharmacology

Received: 19 July 2021 Accepted: 10 November 2021 Published: 16 December 2021

Citation:

De Araújo ERD, Guerra GCB, Andrade AWL, Fernandes JM, Da Silva VC, De Aragão Tavares E, De Araújo AA, de Araújo Júnior RF and Zucolotto SM (2021) Gastric Ulcer Healing Property of Bryophyllum pinnatum Leaf Extract in Chronic Model In Vivo and Gastroprotective

Activity of Its Major Flavonoid.

Front. Pharmacol. 12:744192. doi: 10.3389/fphar.2021.744192

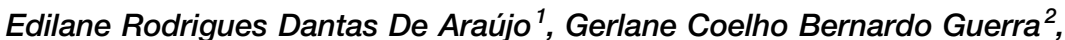
Anderson Wilbur Lopes Andrade ${ }^{3}$, Júlia Morais Fernandes ${ }^{4}$, Valéria Costa Da Silva ${ }^{3}$, Emanuella De Aragão Tavares ${ }^{3}$, Aurigena Antunes De Araújo ${ }^{2}$, Raimundo Fernandes de Araújo Júnior ${ }^{1,5,6,7}$ and Silvana Maria Zucolotto ${ }^{1,3,4 *}$

${ }^{1}$ Postgraduate Program in Health Science, Federal University of Rio Grande do Norte (UFRN), Natal, Brazil, ${ }^{2}$ Department of Biophysics and Pharmacology, Federal University of Rio Grande do Norte, Natal, Brazil, ${ }^{3}$ Postgraduate Program in Drug Development and Technological Innovation, Federal University of Rio Grande do Norte, Natal, Brazil, ${ }^{4}$ Postgraduate Program in Pharmaceutical Science, Federal University of Rio Grande do Norte (UFRN), Natal, Brazil, ${ }^{5}$ Postgraduate Program in Functional and Structural Biology, Department of Morphology, Federal University of Rio Grande do Norte (UFRN), Natal, Brazil, ${ }^{6}$ Translational Nanobiomaterials and Imaging (TNI) Group, Radiology Department, Leiden University Medical Centrum, Leiden, Netherlands, ${ }^{7}$ Percuros B.V, Leiden, Netherlands

Gastric ulcer is a common disease that develops complications such as hemorrhages and perforations when not properly treated. Extended use of drugs in the treatment of this pathology can provoke many adverse effects. Therefore, finding medicinal plants with gastroprotective and mucosal healing properties has gained increasing interest. Bryophyllum pinnatum (Crassulaceae), popularly known in Brazil as "saião" or "coirama," has been used to treat inflammatory disorders. It is rich in flavonoids, and quercetin 3-O- $\alpha$-L-arabinopyranosyl-( $1 \rightarrow 2)-O-\alpha-L-r h a m n o p y r a n o s i d e-B p 1$ is its major compound. In this study, we aimed to investigate ulcer healing properties of $B$. pinnatum against an acetic acid-induced chronic ulcer model and the gastroprotective activity of Bp1 against gastric lesions induced by ethanol and indomethacin. Ultrafast liquid chromatography was used to quantify the main compounds ( $\mathrm{mg} / \mathrm{g}$ of the extract) quercetin 3-O- $\alpha$-L-arabinopyranosyl-( $1 \rightarrow 2)-O-\alpha-L-r h a m n o p y r a n o s i d e ~(33.12 \pm 0.056)$, kaempferol 3-O- $\alpha$-L-arabinopyranosyl-(1 $\rightarrow 2)-O-\alpha$-L-rhamnopyranoside (3.98 \pm 0.049 ), and quercetin 3-O- $\alpha$-L-rhamnopyranoside $(4.26 \pm 0.022)$ and showed good linearity, specificity, selectivity, precision, robustness, and accuracy. In vivo studies showed that treatment with the extract at 250 and $500 \mathrm{mg} / \mathrm{kg}$ stimulated the healing process in the gastric mucosa with significant ulceration index reduction, followed by improvement in the antioxidant defense system [increased glutathione (GSH) levels, decreased superoxide dismutase upregulation, and malondialdehyde (MDA) levels]. Moreover, the extract decreased interleukin-1 $\beta$ and tumor necrosis factor-a levels and myeloperoxidase (MPO) activity, increased interleukin 10 levels, showed a cytoprotective effect in histological analyzes and also downregulated the expression of cyclooxygenase-2 and $\mathrm{NF}-\mathrm{kB}$ (p65). The pretreatment with $\mathrm{Bp} 1$ at a dose of $5 \mathrm{mg} / \mathrm{kg}$ reduced gastric lesions in 
the ethanol and indomethacin models, increased GSH, and decreased MDA levels. In addition, the pretreatment decreased MPO activity, interleukin-1 $\beta$ and tumor necrosis factor- $\alpha$ levels, while also showing a cytoprotective effect in histological analyzes. Our study suggests that treatment with $B$. pinnatum extract showed a higher inhibition percentage than pretreatment with the Bp1. This might in turn suggest that Bp1 has gastroprotective activity, but other compounds can act synergistically, potentiating its effect. We conclude that $B$. pinnatum leaf extract could be a new source of raw material rich in phenolic compounds to be applied in food or medicine.

Keywords: gastric ulcer, ulcer healing, gastroprotection, Bryophyllum pinnatum, flavonoids, quercetin

\section{INTRODUCTION}

Gastric ulcer is one of the most common gastrointestinal disorders which affects the worldwide population. It is estimated that approximately $10 \%$ of the world population develops this disease, which represents a serious health problem with a large impact on the quality of life of millions of individuals (Havens et al., 2018). Gastric ulcer can penetrate the muscular layers of the stomach, developing acute lesions in the gastric mucosa, and it leads to chronic inflammation when not properly treated and could lead to complications such as hemorrhages and perforations (Tarnawski, 2005; Wang et al., 2018).

The development of gastric ulcer results from an imbalance between some offensive and defensive factors in the stomach. The offensive factors include endogenous pathogenic agents and events [hydrochloric acid, pepsin, lipid peroxidation, and production of reactive oxygen species (ROS)] and also exogenous factors [Helicobacter pylori infection, stress, smoking, excessive alcohol consumption, and prolonged use of non-steroid anti-inflammatory drugs (NSAIDs)] (Graham, 2014; Asali et al., 2018). The defensive factors include prostaglandins (PGs), mucin secretion, mucus-bicarbonate barrier, nitric oxide (NO), growth factors, mucosal blood flow, cell regeneration, surface phospholipids, and endogenous antioxidants (Asali et al., 2018).

The main therapeutic intervention for the gastric ulcer is the inhibition of aggressive factors combined with the stimulation of increased defensive factors (Wang et al., 2018). The existing therapeutic drugs for the treatment of this pathology are proton pump inhibitors (PPIs-lansoprazole, omeprazole) and H2-receptor antagonists (H2Ras-ranitidine, famotidine), in addition to antibiotics used to eradicate H. pylori (Scally et al., 2018).

However, prolonged use of antisecretory drugs can cause many adverse effects (Kuna et al., 2019; Weltermann et al., 2021). For example, PPIs can cause abdominal pain, nausea, headache, diarrhea, osteoporosis, and fractures, in addition to pneumonia, insomnia, and kidney inflammation (Amang et al., 2017), and be associated with an increased gastric cancer risk (Weltermann et al., 2021). The long-term use of H2Ras can lead to the development of galactorrhea in women, gynecomastia in men, and alteration of the bacterial flora of the gastrointestinal tract (Youn et al., 2018).
The use of PPIs and H2Ras can also lead to rapid tolerance during treatment, followed by a rebound effect of gastric hypersecretion after withdrawal of the drug, and ulcers may develop again (Youn et al., 2018). Therefore, it is necessary to investigate new therapeutic alternatives with fewer adverse effects, which stimulate the ulcer healing process and prevent new relapses. In this context, the use of medicinal plants and derived phytochemicals has gained growing interest in the search for new drugs with less side effects (Bungãu and Popa, 2015) and to combat inflammation and oxidative stress in a more natural, drug-free fashion (de Moraes et al., 2020).

Bryophyllum pinnatum (Lam) Pers. [synonym B. calycinum and Kalanchoe pinnata (Lam) Pers.] species, popularly known in Brazil as "saião" or "coirama," is native to Madagascar and belongs to the Crassulaceae family. This family has xeromorphic characteristics which enable its species to adapt to the high incidence of sunlight and water scarcity (Herrera, 2008). In view of this, although B. pinnatum is native to Madagascar, it has adapted well to Brazil, mainly to the Caatinga biome (Allorge-Boiteau, 1996; Gehrig et al., 2001), being considered naturalized and not endemic from Brazil (Zappi, 2015).

B. pinnatum has been used in traditional medicine in treating inflammatory disorders (Amaral et al., 2005), gastritis, and ulcer problems (The Plant List, 2010; Fernandes et al., 2019). Furthermore, in our previous study, it was observed that the leaf extracts of this species showed gastroprotective effects in acute gastric lesions induced by ethanol and indomethacin in rats (Araújo et al., 2018). The literature describes the presence of phenolic compounds in the leaves of this species, highlighting the presence of flavonoids. Glycosides derived from quercetin, patuletin, eupafolin, and kaempferol have been identified in $B$. pinnatum leaf extract (Muzitano et al., 2006; Afzal et al., 2012; Fernandes et al., 2016; Araújo et al., 2018).

Quercetin3-O- $\alpha$-L-arabinopyranosyl-( $1 \rightarrow 2)$-O- $\alpha$-L-rhamnopyranoside is a flavonoid isolated from B. pinnatum leaves, being considered the major compound and marker for this species (Nascimento et al., 2018; Fernandes et al., 2021). This compound contains a rare sugar moiety and has shown antiinflammatory and leishmanicidal activities (Muzitano et al., 2006; Ferreira et al., 2014), therefore is a possible marker for the species.

Quercetin, one such member of the flavonoid family, is one of the most prominent dietary antioxidants, more active than the well-known vitamins E and C antioxidants (Russo et al., 2012; 


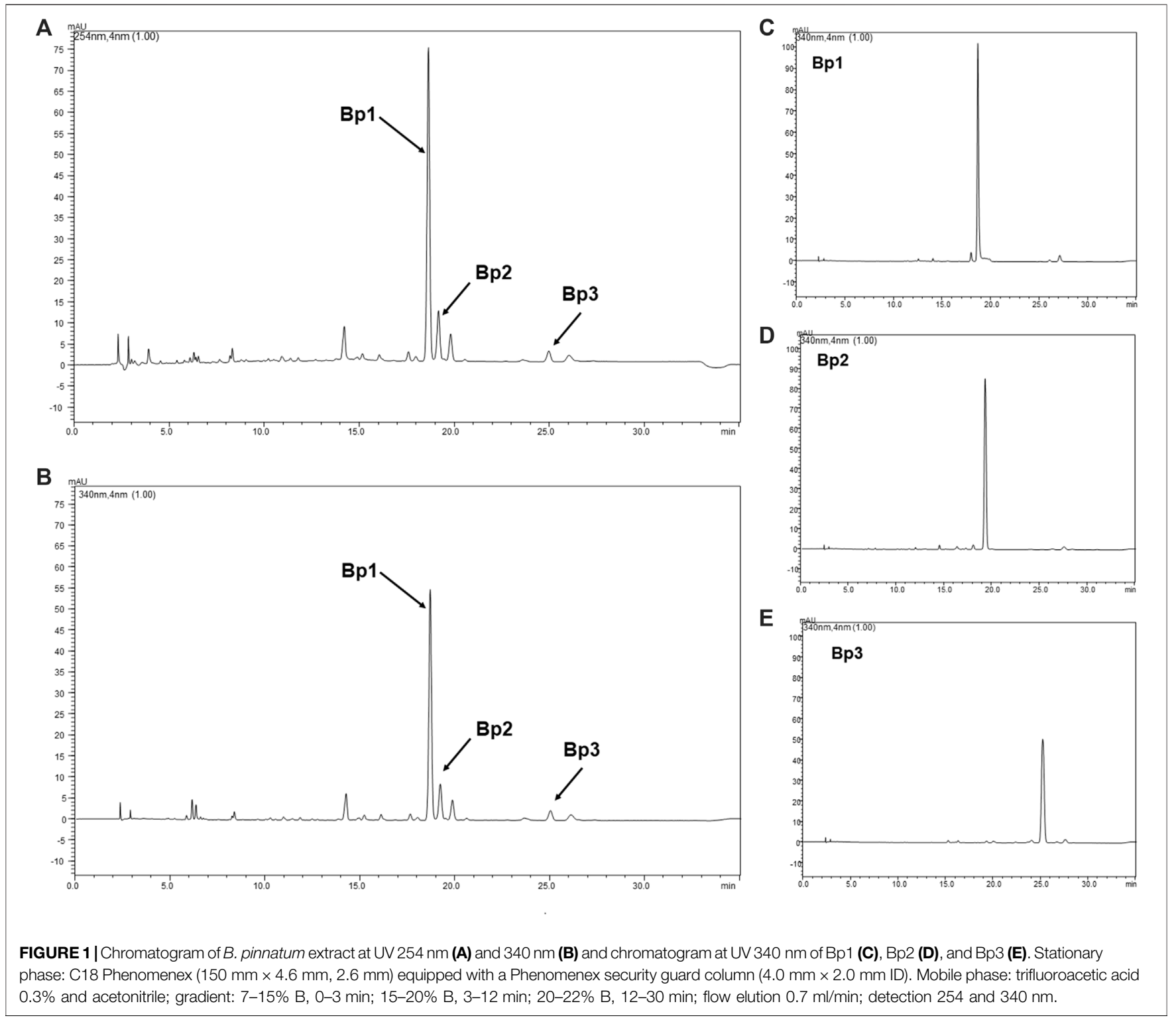

Farzaei et al., 2015). Quercetin has been reported to have protective effects against various diseases such as osteoporosis, certain cancers, pulmonary and cardiovascular diseases, and aging and has been reported to prevent gut microbiota dysbiosis, in addition to presenting antioxidant and anti-inflammatory activities (Bhutada et al., 2010; Kumari et al., 2010; Russo et al., 2012; Wu et al., 2012; Cardona et al., 2013; Etxeberria et al., 2015; Farzaei et al., 2015).

Considering the promising preliminary results with $B$. pinnatum leaf extract in acute gastric lesions induced by ethanol and indomethacin and the relevant therapeutic potential of this species, this work has the objective to evaluate ulcer healing properties of $B$. pinnatum leaf extract against an acetic acid-induced chronic ulcer model in rats and the gastroprotective activity of quercetin 3-O-
$\alpha$-L-arabinopyranosyl-( $1 \rightarrow 2)-O-\alpha$-L-rhamnopyranoside against gastric lesions induced by ethanol and indomethacin in mice, and to quantify the flavonoid content by ultrafast liquid chromatography analysis.

\section{MATERIALS AND METHODS}

\section{Plant Material and Reagents}

B. pinnatum leaves were collected from the "Escola Agrícola de Jundiaí" in Macaíba city, Rio Grande do Norte state, Brazil, in the February of 2018. The botanical identification voucher specimen (No. 57335) was deposited at the herbarium of the Bioscience Center of the Federal University of Rio Grande do Norte. The collection was authorized by the Brazilian Authorization and Biodiversity Information System (SISBIO process No. 35017), 
<smiles>CC1OC2OC3=C(c4ccc(O)c(O)c4)Oc4cc(O)cc(O)c4C(=O)C3=C(OC3OCC(O)C(O)C3O)C2OC2C(O)C(O)C(O)C(O)C2O1</smiles>

Bp1<smiles></smiles>

Bp2<smiles>Cc1cc(O)c2c(=O)c(OC3OC(C)C(O)C(O)C3O)c(-c3ccc(O)c(O)c3)oc2c1</smiles>

Bp3

FIGURE 2 | Structures of the flavonoids (A) quercetin 3-O- $\alpha-L$-arabinopyranosyl-(1 $\rightarrow 2)-O-\alpha-L-$ rhamnopyranoside (Bp1), (B) kaempferol 3-O- $\alpha-L-$

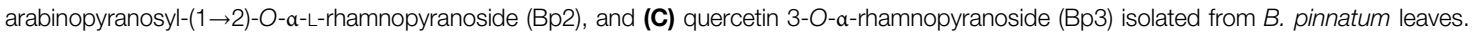

and the research was authorized by the National System for the Management of Genetic Heritage and Associated Traditional Knowledge (SISGEN process no. A7EA798).

Most of the chemicals used were purchased from SigmaAldrich (São Paulo, Brazil, Madrid, Spain), unless otherwise stated. Quercetin 3-O- $\alpha$-L-arabinopyranosyl-( $1 \rightarrow 2)-O-\alpha-$ L-rhamnopyranoside (Bp1) (99.3\% purity), kaempferol 3-O$\alpha$-L-arabinopyranosyl-( $1 \rightarrow 2)-O-\alpha$-L-rhamnopyranoside (Bp2) (98.9\% purity), and quercetin 3-O-a-L-rhamnopyranoside (Bp3) (99.6\% purity) were previously isolated from $B$. pinnatum and identified by nuclear magnetic resonance (NMR) and mass spectrometry (MS). The purity of the isolated compounds was determined by software of ultrafast liquid chromatography (UFLC) coupled with a diode-array detector (DAD) (Shimadzu Model LC-20AD, with DAD detector model SPD-M20A). NMR analysis of each sample also showed integration signals related to one compound (results not shown).

\section{Preparation of the Bryophyllum pinnatum Leaf Extract}

Fresh B. pinnatum leaves $(4.3 \mathrm{~kg})$ were processed by turbo extraction with water in a proportion of $1: 1(\mathrm{w} / \mathrm{v})$ in an industrial blender for $5 \mathrm{~min}$ to obtain the $B$. pinnatum leaf extract. The extract was sieved and concentrated on a rotoevaporator (model V-700, Buchi, Flawil, Switzerland) and freeze-dried (extraction yield of $4.40 \%$ ). For in vivo assays, the extract was solubilized in distilled water.

\section{Isolation and Identification of Main Flavonoids From B. pinnatum}

The main flavonoids from $B$. pinnatum were previously isolated and identified by Fernandes et al. (2021). Three compounds [quercetin 3-O- $\alpha$-L-arabinopyranosyl-( $1 \rightarrow 2)-O-\alpha$-L-rhamnopyranoside (Bp1), kaempferol 3-O- $\alpha$-L-arabinopyranosyl-(1 $\rightarrow 2)-O-\alpha$ L-rhamnopyranoside (Bp2), and quercetin 3-Oa-L-rhamnopyranoside (Bp3)] were efficiently purified; all of them as amorphous yellow powder. The compounds yield provided $149.4 \mathrm{mg}$ of $\mathrm{Bp} 1,14.1 \mathrm{mg}$ of $\mathrm{Bp} 2$, and $6.7 \mathrm{mg}$ of Bp3. Details about the isolation and structural elucidation can be obtained in Fernandes et al. (2021).

\section{Quantitative Analyses of Flavonoids Bp1, Bp2, and Bp3 by UFLC-DAD}

B. pinnatum extract was analyzed by UFLC-DAD (Shimadzu Model LC-20AD, Kyoto, Japan, with DAD detector model SPDM20A and LabSolutions software, Shimadzu, Kyoto, Japan). The method used was validated according to Brazilian legislation No. 166 from July 24, 2017 (Brazil, 2017), which is aligned with the Guideline Q2 (R1) of the International Conference on Harmonisation of Technical Requirements for Registration of Pharmaceuticals for Human Use (ICH, 2005). The following parameters were analyzed: selectivity, linearity, limits of detection (LOD) and limits of quantification (LOQ), precision, accuracy, and robustness. Prior to starting the validation, the system suitability of the developed method was verified according to the parameters established in the United States Pharmacopeia to guarantee resolution $(\mathrm{R}>1.5)$, column efficiency $(p>2,000)$, tailing factor $(\mathrm{T} \leq 2.0)$, and capacity factor $\left(\mathrm{k}^{\prime} \geq 2.0\right)$ for each peak to be subsequently quantified (USP, 2003). All analyses were performed in triplicate, and the relative standard deviation was calculated. The samples ( $B$. pinnatum extract and Bp1) were resuspended in 1:1 methanol:water $(\mathrm{v} / \mathrm{v})$, and the extract was analyzed at the concentration of $2 \mathrm{mg} / \mathrm{ml}$ and $\mathrm{Bp} 1, \mathrm{Bp} 2$, and $\mathrm{Bp} 3$ at the concentration of $200 \mu \mathrm{g} / \mathrm{ml}$. A Phenomenex Kinetex Core-Shell $\mathrm{RP}-18$ column $(150 \mathrm{~mm} \times 4.6 \mathrm{~mm}, 2.6 \mathrm{~mm}$ particle size $)$ equipped with a Phenomenex security guard column $(4.0 \mathrm{~mm} \times 2.0 \mathrm{~mm}$ ID) was used. The eluents were 1) trifluoroacetic acid $0.3 \%$ and 2) acetonitrile. The following gradient (v/v) was applied: 7-15\% B, 0-3 min; 15-20\% B, 3-12 min; 20-22\% B, 12-30 min; with $30 \mathrm{~min}$ of analysis time. Flow elution was $0.7 \mathrm{ml} / \mathrm{min}$, and $12 \mathrm{ml}$ of each sample was injected. The UV-DAD detector was programmed for wavelength $200-500 \mathrm{~nm}$, and the chromatogram was plotted at 254 and $340 \mathrm{~nm}$. B. pinnatum is a plant rich in flavonoids, therefore the chromatogram was analyzed at UV $340 \mathrm{~nm}$ and also recorded at 
TABLE 1 | Validation parameters of the analytical method to quantify the content of Bp1, Bp2, and Bp3 in B. pinnatum extract at UV $340 \mathrm{~nm}$.

\begin{tabular}{|c|c|c|c|c|c|c|c|c|c|c|c|}
\hline \multirow[t]{2}{*}{ Compounds } & \multicolumn{3}{|c|}{ System suitability parameters ${ }^{a}$} & \multicolumn{4}{|c|}{ Selectivity parameters } & \multirow{2}{*}{$\frac{\text { Linearity }}{\text { Calibration curve }^{\mathbf{b}}}$} & \multirow[t]{2}{*}{$\operatorname{LOD}^{\mathrm{c}}(\mu \mathrm{g} / \mathrm{ml})$} & \multirow[t]{2}{*}{$\mathrm{LOQ}^{\mathrm{c}}(\mu \mathrm{g} / \mathrm{ml}$} & \multirow[t]{2}{*}{ Content $(\mathrm{mg} / \mathrm{g})$} \\
\hline & $\mathbf{R}$ & $\mathbf{T}$ & $\mathbf{P}$ & $\mathbf{k}^{\prime}$ & Peak purity & $R t$ (min.) & $r$ & & & & \\
\hline Bp1 & $1.68 \pm 0.023$ & $1.33 \pm 0.201$ & $51413,23 \pm 435.631$ & $7.77 \pm 0.176$ & $0.99 \pm 0.01$ & $19.20 \pm 0.26$ & 0.9997 & $y=457720 x-11163$ & 0.0001713 & 0.0005191 & $33.12 \pm 0.056$ \\
\hline Bp2 & $2.05 \pm 0.019$ & $1.19 \pm 0.027$ & $41901,22 \pm 298.611$ & $7.83 \pm 0.366$ & $0.98 \pm 0.005$ & $19.87 \pm 0.28$ & 0.9996 & $y=92220 x-698.53$ & 0.0007442 & 0.0022553 & $3.98 \pm 0.049$ \\
\hline Вp3 & $2.61 \pm 0.038$ & $1.03 \pm 0.004$ & $49,248 \pm 343.211$ & $10.49 \pm 0.328$ & $0.99 \pm 0.006$ & $25.58 \pm 0.20$ & 0.9992 & $y=194,10 x+198.17$ & 0.0007428 & 0.0006598 & $4.26 \pm 0.022$ \\
\hline \multirow[t]{2}{*}{ Compounds } & & \multicolumn{3}{|c|}{ Intermediate precision $^{d}$} & \multicolumn{3}{|c|}{ Repeatability $^{\mathbf{e}}$} & & \multicolumn{3}{|c|}{ Accuracy $^{f}$} \\
\hline & & $50 \%$ & $100 \%$ & $150 \%$ & $50 \%$ & $100 \%$ & $150 \%$ & & $50 \%$ & $100 \%$ & $150 \%$ \\
\hline Bp1 & RSD (\%) & 3.49 & 3.24 & 0.48 & 0.97 & 0.22 & 0.50 & Recovery (\%) & 111.92 & 98.85 & 90.99 \\
\hline Bp2 & & 1.71 & 1.11 & 1.05 & 1.07 & 2.19 & 0.37 & & 101.07 & 89.70 & 102.16 \\
\hline Вp3 & & 3.28 & 3.29 & 1.47 & 2.01 & 2.59 & 1.68 & & 98.37 & 91.88 & 99.03 \\
\hline
\end{tabular}

$R$, resolution; $T$, tail factor; $P$, column efficiency or theoretical plates; $k^{\prime}$, capacity factor; Rt, retention time; $r$, coefficient of correlation; RSD, relative standard deviation.

${ }^{a}$ Data obtained through the analysis of peak of compounds $\mathrm{Bp} 1, \mathrm{Bp} 2$, and Bp3 from B. pinnatum extract.

${ }^{b} y=$ peak area and $x=$ concentration $(\mathrm{mg} / \mathrm{mll}$.

${ }^{c} L O D=3.3 R / S$ and $L O Q=10 R / S$ : where $R$ and $S$ are the residual standard deviation of the regression line and slope of the calibration curve, respectively.

${ }^{d} R S D$ of the mean of the samples analyzed on three different days $(n=3)$.

${ }^{e} R S D$ of the mean of the samples analyzed on the same day $(\mathrm{n}=3)$.

${ }^{f}$ Accuracy determined by the recovery method were added quantities known of reference substance (Bp1, Bp2, and Bp3) to sample (B. pinnatum extract at $\left.2 \mathrm{mg} / \mathrm{ml}\right)$. 
TABLE 2 | Effect of treatment with B. pinnatum leaf extract (125, 250, and $500 \mathrm{mg} / \mathrm{kg}$ ) in the lesion area and percent inhibition in the acetic acid-induced chronic gastric ulcer model.

\begin{tabular}{lcc} 
Experimental group & Lesion area $\mathbf{( m m )}$ & Inhibition percentage (\%) \\
\hline Ulcerated control & 188.20 & - \\
Lansoprazole $(30 \mathrm{mg} / \mathrm{kg})$ & $17.67^{\star \star \star \star}$ & 92.89 \\
B. pinnatum $(125 \mathrm{mg} / \mathrm{kg})$ & $111.80^{\star}$ & 28.13 \\
B. pinnatum $(250 \mathrm{mg} / \mathrm{kg})$ & $54.80^{\star \star \star \star}$ & 76.46 \\
B. pinnatum $(500 \mathrm{mg} / \mathrm{kg})$ & $47.40^{\star \star \star \star}$ & 81.33
\end{tabular}

Results expressed as mean \pm standard deviation $(\mathrm{n}=6)$. ANOVA and Dunnett post-test were used to calculate the statistical significance, ${ }^{*} \mathrm{p}<0.05$, ${ }^{* *} \mathrm{p}<0.01$ and ${ }^{* * * *} \mathrm{p}<0.0001$ vs. ulcerated control.

UV $254 \mathrm{~nm}$ to verify the presence or absence of other possible secondary metabolites present in the extract (Aparicio and Harwood, 2013). UFLC-grade acetonitrile and trifluoracetic acid were purchased from J. T. Baker (Brazil). Water was purified with a MilliQ system (Millipore, Burlington, Massachusetts, United States). The samples and solvents were filtrated through a membrane (pore size of $0.45 \mathrm{~m}$ ) and degassed. Each sample was analyzed in triplicate.

\section{In Vivo Studies}

Female Wistar rats $(180 \pm 20 \mathrm{~g}, 6-8$ weeks old $)$ were used for the evaluation of ulcer healing in the acetic acid-induced chronic ulcer, and female Swiss albino mice ( $25 \pm 10 \mathrm{~g}, 6-8$ weeks old) were used for the gastroprotective activity in the models of induction of gastric lesions by ethanol and indomethacin. All animals were raised in accordance with the National Institute of Health Guide for Laboratory Animals. Rodents were acclimated for 7 days prior to experimentation, were housed under standard environment conditions at $20-25^{\circ} \mathrm{C}$ and $12-\mathrm{h}$ dark/light cycle, and had free access to potable water (ad libitum) and standard food. These procedures were approved by the Ethics Committee of Laboratory Animals of the Federal University of Rio Grande do Norte (CEUA No. 029.047/2017).

\section{Evaluation of Ulcer Healing Property of $B$. pinnatum Leaf Extract \\ Acetic Acid-Induced Chronic Gastric Ulcer}

Chronic gastric ulcers were induced according to the method described by Okabe et al. (2005). Female Wistar rats were divided randomly into six experimental groups with six animals in each group $(n=6)$ and were fasted $18 \mathrm{~h}$ before the surgical procedure for induction of chronic gastric ulcer. Under anesthesia with ketamine $(50 \mathrm{mg} / \mathrm{kg})$ and xylazine $(5 \mathrm{mg} / \mathrm{kg})$ by intraperitoneal (IP) injection, laparotomy was performed through a midline epigastric incision; the stomach was exposed and $80 \%$ acetic acid $(0.03 \mathrm{ml})$ was instilled for $1 \mathrm{~min}$ into the subserosal layer of the glandular portion, using a microsyringe $(0.05 \mathrm{ml})$ and a cannula ( $6 \mathrm{~mm}$ of diameter). Afterward, the fluid was aspirated off carefully and the area that remained in contact with the acid was gently rinsed with sterile saline solution. Then, the stomach was located to the anatomical region, and the anterior wall of the abdomen closed by continuous 2.0 silk suture. Forty-eight hours after ulcer induction, the rats were orally treated with vehicle (distilled water, $10 \mathrm{ml} / \mathrm{kg}$ ), lansoprazole $(30 \mathrm{mg} / \mathrm{kg})$, and B. pinnatum leaf extract in the doses of 125,250 , and $500 \mathrm{mg} / \mathrm{kg}$, respectively, twice a day for 7 days. On the following day, the animals were euthanatized by cervical dislocation under anesthesia [ketamine $(80 \mathrm{mg} / \mathrm{kg})$ and xylazine $(10 \mathrm{mg} / \mathrm{kg}, \mathrm{IP})]$, and the stomachs were removed and opened along the greatest curvature, washed with sterile saline solution, and then macroscopically evaluated for measuring the injured areas. The stomach samples were stored at $-80^{\circ} \mathrm{C}$ for analyses.

\section{Gastroprotective Activity of Quercetin 3-O-a-L-Arabinopyranosyl $-(1 \rightarrow 2)-O-\alpha-L-R h a m n o p y r a n o s i d e ~(B p 1)$} Ethanol-Induced Gastric Lesions

The induction of gastric lesion by ethanol was adapted from the method of Hollander and Tarnawski (1986). After $24 \mathrm{~h}$ of fasting, the mice ( $n=7$ /group) were orally pretreated at 24 and $1 \mathrm{~h}$ prior to induction. The Healthy Group and the Gastric Lesion Group received the vehicle (distilled water, $10 \mathrm{ml} / \mathrm{kg}$ ) orally. The group pretreated with the standard drug received an oral dose of the $50 \mathrm{mg} / \mathrm{kg}$ ranitidine, and the groups pretreated with Bp1 received an oral dose of 2.5, 5, and $10 \mathrm{mg} / \mathrm{kg}$. After $1 \mathrm{~h}$ of the pretreatment, all animals except those in the Healthy Group received an oral dose of the $0.5 \mathrm{ml} / 100 \mathrm{~g}$ absolute ethanol PA. The mice were euthanized $1 \mathrm{~h}$ later by cervical dislocation under anesthesia [ketamine $(80 \mathrm{mg} / \mathrm{kg})$ and xylazine $(10 \mathrm{mg} / \mathrm{kg}, \mathrm{IP})]$, the stomachs were removed and opened along the greatest curvature, washed with sterile saline solution, and then macroscopically evaluated for measuring the injured areas. The stomach samples were stored at $-80^{\circ} \mathrm{C}$ for analyses.

\section{Indomethacin-Induced Gastric Lesions}

The induction of gastric lesion by indomethacin was adapted from the method of Kakub and Gulfraz (2007). After $24 \mathrm{~h}$ of fasting, the mice ( $n=7$ /group) were orally pretreated at 24 and $1 \mathrm{~h}$ prior to induction. The Healthy Group and the Gastric Lesion Group received the vehicle (distilled water, $10 \mathrm{ml} / \mathrm{kg}$ ) orally. The group pretreated with the standard drug received an oral dose at $50 \mathrm{mg} / \mathrm{kg}$ ranitidine, and the groups pretreated with Bp1 received an oral dose at 2.5, 5, and $10 \mathrm{mg} / \mathrm{kg}$. After $1 \mathrm{~h}$ of the pretreatment, all animals except those in the Healthy Group received an oral dose of the $40 \mathrm{mg} / \mathrm{kg}$ indomethacin. The mice were euthanized $6 \mathrm{~h}$ later by cervical dislocation under anesthesia with ketamine $(80 \mathrm{mg} / \mathrm{kg}$ ) and xylazine $(10 \mathrm{mg} / \mathrm{kg}$, IP), the stomachs were removed and opened along the greatest curvature, washed with sterile saline solution, and then macroscopically evaluated for measuring the injured areas. The stomach samples were stored at $-80^{\circ} \mathrm{C}$ for analyses.

\section{Macroscopic Stomach Lesion Assessment}

In order to determine the Gastric Lesion Index (GLI), the scores were attributed as described by Magistretti et al. (1988) with adaptations. The extent of gastric damage was quantified by measuring the area of gastric lesions. The stomach was thoroughly rinsed with sterile saline solution to remove any contents. Then, the stomach samples were photographed. The digital photos were used for the determination of the total stomach area $\left(\mathrm{mm}^{2}\right)$ and area of the gastric lesions $\left(\mathrm{mm}^{2}\right)$ using Image $1.48 \mathrm{~d}$ software (National Institute of Health, Bethesda, MD, United States). For each stomach, the sum of the areas of 


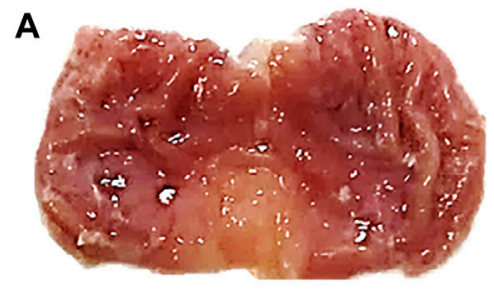

D

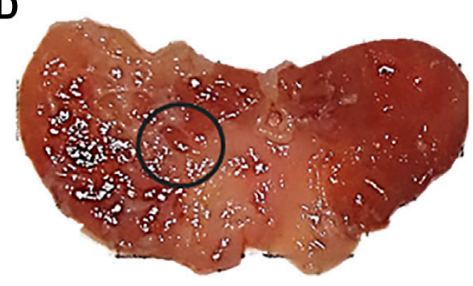

B

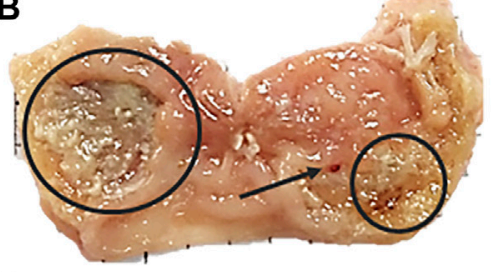

E

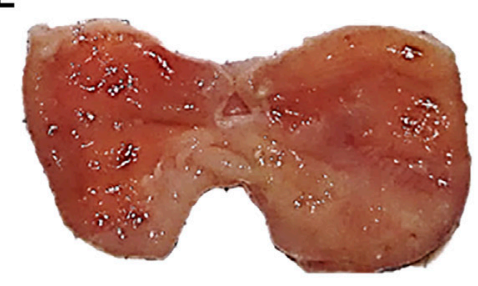

C

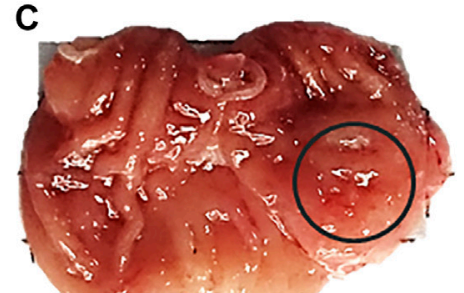

$\mathbf{F}$

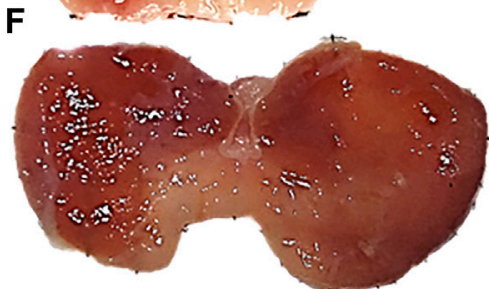

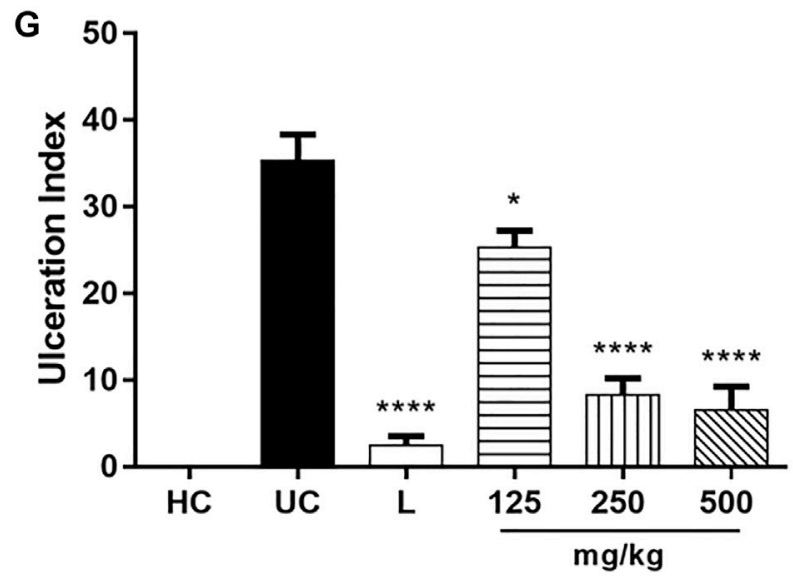

B. pinnatum

FIGURE 3 | Effect of treatment with B. pinnatum leaf extract (125, 250, and $500 \mathrm{mg} / \mathrm{kg}$ ) on the acetic acid-induced chronic gastric ulcer model in rats (A) healthy; (B) gastric lesion control; (C) lansoprazole 30 mg/kg; (D) B. pinnatum 125 mg/kg; (E) B. pinnatum 250 mg/kg; (F) B. pinnatum 500 mg/kg. (G) Results expressed as mean \pm standard mean error $(n=6)$. ANOVA and Dunnett post-test were used to calculate the statistical significance, ${ }^{\star} p<0.05$, ${ }^{\star \star} p<0.01$, and ${ }^{\star \star \star \star} p<0.0001$ vs. ulcerated control. Healthy control, HC; ulcerated control, UC; lansoprazole (30 mg/kg), L.

all forms of gastric lesions was recorded. The GLI and Percentage Inhibition (I\%) were calculated according to the following equations:

$G L I=\left[\right.$ lesion area $\left(\mathrm{mm}^{2}\right) /$ total stomach area $\left.\left(\mathrm{mm}^{2}\right)\right] \times 100$, $I \%=[(\mathrm{GLI}$ gastric lesiongroup

- GLI pre - treated group)/GLI gastric lesion contro] $\times 100$.

\section{Nonprotein Sulfhydryls Assay}

Glutathione (GSH) levels in gastric tissue were measured as a marker of antioxidant activity. The stomach samples were harvested and stored at $-80^{\circ} \mathrm{C}$ until required for the assay. The gastric tissue homogenate $(0.25 \mathrm{ml} 5 \%$ tissue solution prepared in $0.02 \mathrm{M}$ ethylenediaminetetraacetic acid) was added to $320 \mu \mathrm{l}$ distilled water and $80 \mu \mathrm{l} 50 \%$ trichloroacetic acid. The samples were centrifuged at
3,000 rpm and $4^{\circ} \mathrm{C}$ for $15 \mathrm{~min}$. Then, $400 \mu \mathrm{l}$ supernatant was added to $800 \mu \mathrm{l} 0.4 \mathrm{M}$ Tris buffer ( $\mathrm{pH}$ 8.9) and $20 \mu \mathrm{l}$ $0.01 \mathrm{M}$ 5,5'-dithio-bis-[2-nitrobenzoic acid]. Sample absorbance was measured at $420 \mathrm{~nm}$. The results were reported as units of GSH per milligram of tissue.

\section{Malondialdehyde Assay}

Malondialdehyde (MDA) content was measured by the assay described by Esterbauer and Cheeseman (1990). The stomach samples were suspended in buffer Tris hydrochloric acid (HCl) 1: $5(\mathrm{w} / \mathrm{v}), \mathrm{pH}=7.4$, and minced with scissors for $15 \mathrm{~s}$ on an ice-cold plate. The resulting suspension was homogenized for 2 min with an automatic Potter homogenizer and centrifuged at 2,500 $\times g$ at $4^{\circ} \mathrm{C}$ for $10 \mathrm{~min}$. The supernatants were assayed to determine the MDA content. Chromogen reagent 1-methyl-2-phenylindole was used in the reaction. The absorbance was measured at $586 \mathrm{~nm}$ and was calculated by interpolation in standard curve with $1,1,3,3$ 


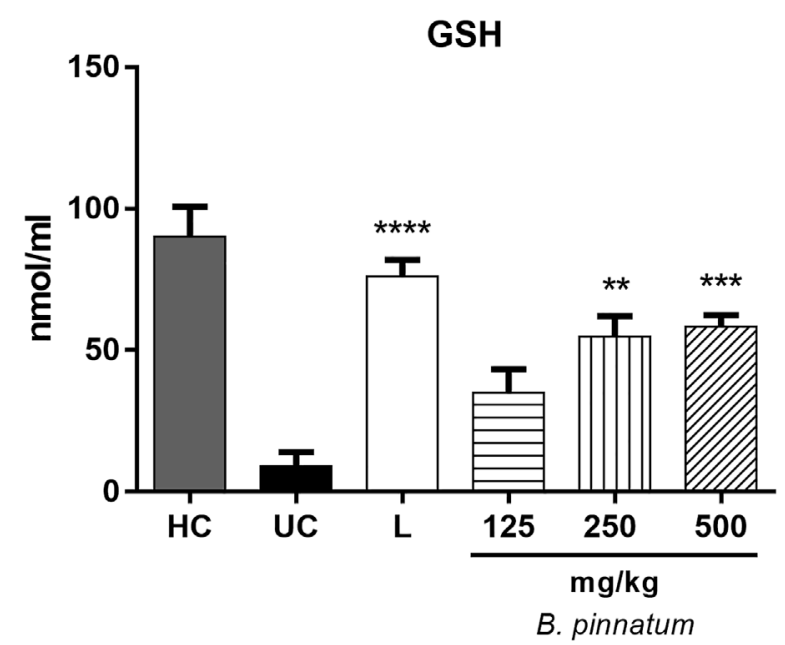

FIGURE 4 |Effect of treatment with B. pinnatum leaf extract (125, 250, and $500 \mathrm{mg} / \mathrm{kg})$ on GSH levels in the acetic acid-induced chronic gastric ulcer model in rats. Results expressed as mean \pm standard mean error $(n=6)$. ANOVA and Tukey post-test were used to calculate the statistical significance, ${ }^{\star \star} p<0.01,{ }^{\star \star \star} p<0.001,{ }^{\star \star \star \star} p<$ 0.0001 vs. ulcerated control. Healthy control, HC; ulcerated control, UC; lansoprazole (30 mg/kg), L.

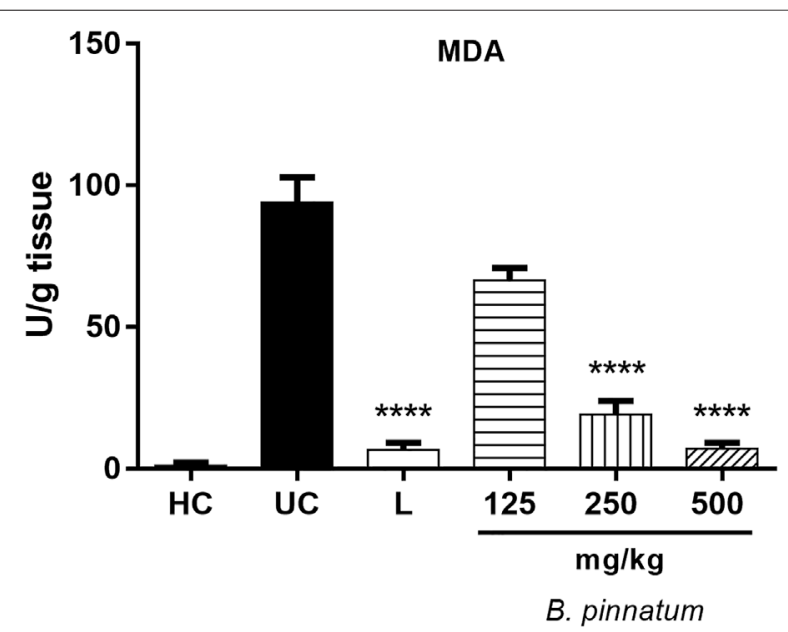

FIGURE 5|Effect of treatment with B. pinnatum leaf extract (125, 250, and $500 \mathrm{mg} / \mathrm{kg}$ ) on MDA levels in the acetic acid-induced chronic gastric ulcer model in rats. Results expressed as mean \pm standard mean error $(n=6)$. ANOVA and Tukey post-test were used to calculate the statistical significance, ${ }^{\star \star \star \star} p<0.0001$ vs. ulcerated control. Healthy control, HC; ulcerated control, UC; lansoprazole (30 mg/kg), L.

tetraethoxypropane $(10 \mathrm{mM})$, hydrolyzed during incubation with $\mathrm{HCl}$ at $45^{\circ} \mathrm{C}$ for $40 \mathrm{~min}$. The results are expressed as nanomoles of MDA per gram of tissue.

\section{Myeloperoxidase Activity}

The stomach samples were harvested as described above and stored at $-80^{\circ} \mathrm{C}$ until required for the assay. After homogenization in hexadecyltrimethylammonium bromide $0.5 \%(\mathrm{pH}=6.0)$, and centrifugation $\left(2000 \times g\right.$ for $20 \mathrm{~min}$ at $\left.4^{\circ} \mathrm{C}\right)$, myeloperoxidase (MPO) activity was determined by a previously described colorimetric method (Krawisz et al., 1984). o-Dianisidine dihydrochloride staining reagent, potassium phosphate buffer $(\mathrm{PB})$, and $0.05 \%$ hydrogen peroxide at $1 \%$ were used in this reaction. The absorbance of the samples was determined at $450 \mathrm{~nm}$ in a 96-well microplates reader. The results were expressed as the amount of enzyme that degrades $1 \mu \mathrm{mol} \mathrm{ml}{ }^{-1}$ of peroxide at $25^{\circ} \mathrm{C}$ and reported as units of MPO per gram of tissue.

\section{Interleukin-1 $\beta$, Tumor Necrosis Factor- $\alpha$, and Interleukin-10 Assays}

The tissue was homogenized and processed as described by Safieh-Garabedian et al. (1995). The levels of interleukin-1 $\beta$ (IL-1 $\beta$ ) [detection range: $62.5-4,000 \mathrm{pg} / \mathrm{ml}$; sensitivity or lower limit of detection (LLD): $12.5 \mathrm{ng} / \mathrm{ml}$ of recombinant mouse IL- 


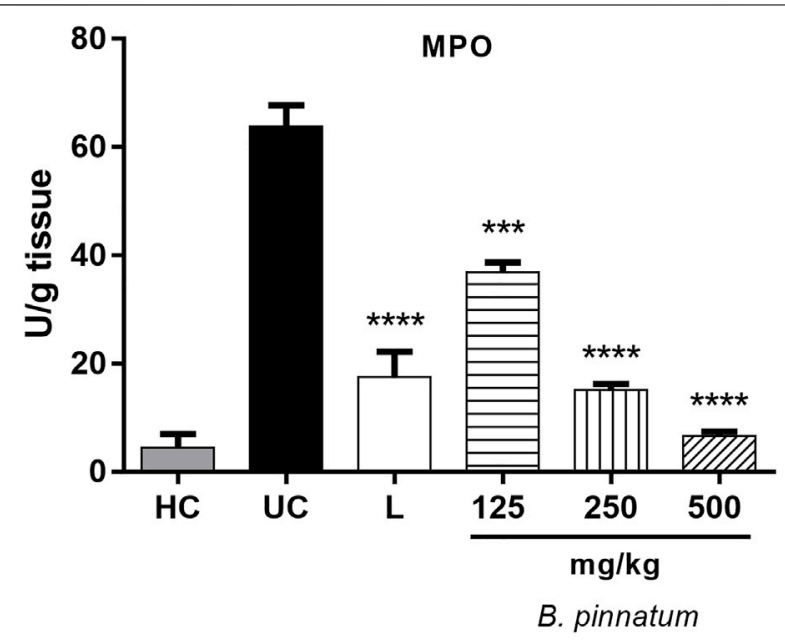

FIGURE 6 | Effect of treatment with B. pinnatum leaf extract (125, 250, and $500 \mathrm{mg} / \mathrm{kg})$ on MPO enzyme activity in the acetic acid-induced chronic gastric ulcer model in rats. Results expressed as mean \pm standard mean error $(n=6)$. ANOVA and Tukey post-test were used to calculate the statistical significance, ${ }^{\star \star \star} p<0.001$, ${ }^{\star \star \star \star} p<0.0001$ vs. ulcerated control. Healthy control, HC; ulcerated control, UC; lansoprazole (30 mg/kg), L.

A

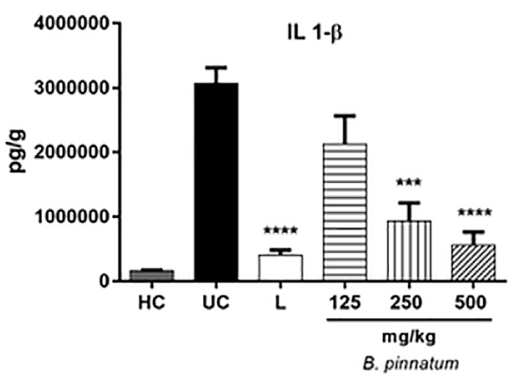

B

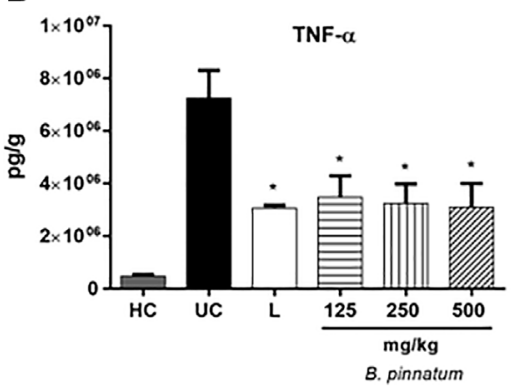

C

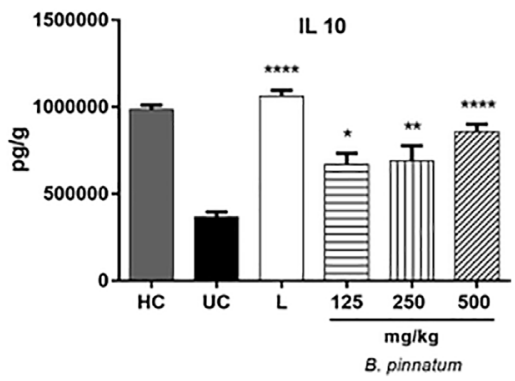

FIGURE 7 | Effect of treatment with B. pinnatum leaf extract (125, 250, and $500 \mathrm{mg} / \mathrm{kg}$ ) on IL-1 $\beta$, TNF- $\alpha$, and IL-10 levels in the acetic acid-induced chronic gastric ulcer model in rats. Results expressed as mean \pm standard mean error $(n=6)$. ANOVA and Tukey post-test were used to calculate the statistical significance, ${ }^{\star} p<0.05$, ${ }^{\star \star} p<0.01,{ }^{\star \star \star} p<0.001,{ }^{\star \star \star \star} p<0.0001$ vs. ulcerated control. Healthy control, HC; ulcerated control, UC; lansoprazole (30 mg/kg), L.

$1 \beta]$, tumor necrosis factor- $\alpha$ (TNF- $\alpha$ ) (detection range: 62.5-4,000 pg/ml; sensitivity or LLD: $50 \mathrm{ng} / \mathrm{ml}$ of recombinant mouse TNF- $\alpha$ ), and interleukin-10 (IL-10) (detection range: $62.5-4,000 \mathrm{pg} / \mathrm{ml}$; sensitivity or LLD: $50 \mathrm{ng} / \mathrm{ml}$ of recombinant mouse IL-10) in the stomach samples were determined with a commercial ELISA kit (R\&D Systems, Minneapolis, MN, United States), as previously described. All samples were within the wavelength used in UV-VIS spectrophotometry (absorbance measured at $490 \mathrm{~nm}$ ).

\section{Histopathology Analysis}

The specimens of the gastric walls for all the animal groups were fixed in $10 \%$ buffered formalin solution and processed by light microscopy using the paraffin slice technique. The sections with $4 \mu \mathrm{m}$ thickness were stained with hematoxylin and eosin (H\&E) stain for histological evaluation. The criteria for evaluating gastric lesions and leukocyte infiltration and distribution were carried out according to the parameters described by Dokmeci et al. (2005). Reported histopathological analyses were independently performed by two pathologists, blinded to the group identity.

\section{Immunohistochemical Staining of Superoxide Dismutase, Cyclooxygenase-2, and Nuclear Factor-Kappa B-p65}

Thin stomach sections $(3 \mu \mathrm{m})$ were obtained from each group of the chronic ulcer experiment (Healthy Group, Gastric Lesion Group, lansoprazole, and dose of $250 \mathrm{mg} / \mathrm{kg}$ and $500 \mathrm{mg} / \mathrm{kg}$ of $B$. pinnatum leaf extract) with a microtome and transferred to gelatine-coated slides. Each tissue section was then deparaffinized and rehydrated. The stomach tissue slices were washed with $0.3 \%$ Triton X-100 in PB and quenched with endogenous peroxidase $(3 \%$ hydrogen peroxide). The tissue sections were incubated overnight at 

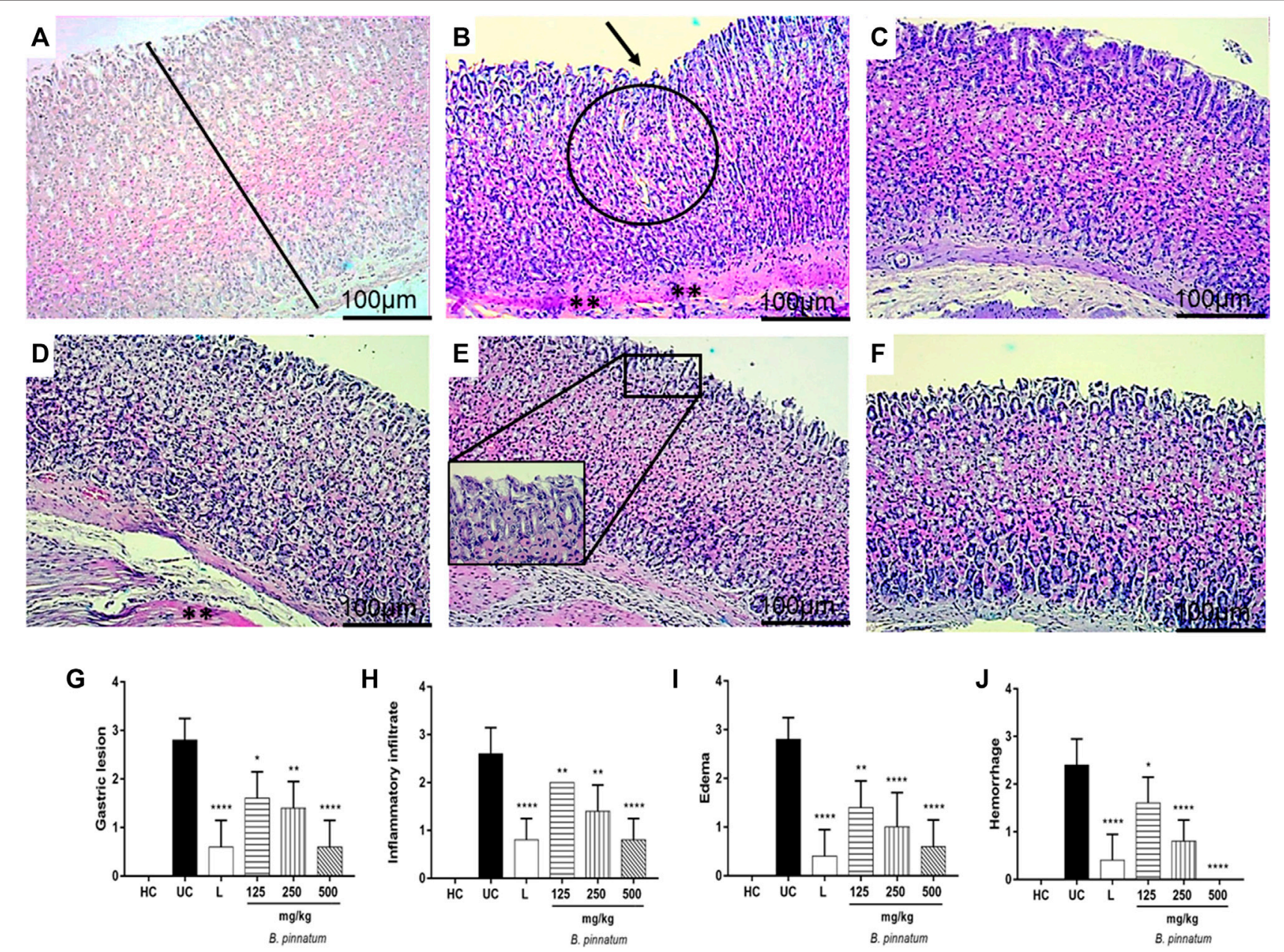

FIGURE 8 | Effect of treatment with B. pinnatum leaf extract $(125,250$, and $500 \mathrm{mg} / \mathrm{kg})$ in the histology of acetic acid-induced chronic gastric ulcer model in rats. Histopathological characteristics of the gastric tissue of rats, showing the cut of the stomach in the transverse direction. The H\&E stained slides were visualized under a bright field microscope with $\times 10$ magnification. (A) Healthy control; (B) ulcerated control; (C) lansoprazole; (D) B. pinnatum $125 \mathrm{mg} / \mathrm{kg}$; (E) B. pinnatum $250 \mathrm{mg} / \mathrm{kg}$; (F) B. pinnatum $500 \mathrm{mg} / \mathrm{kg}$. The bar indicates gastric mucosa without changes; circle: necrotic lesions; one white arrow: hemorrhage points; one black arrow: distraction of the surface epithelium; two asterisks: intense inflammatory infiltrate; (G) gastric lesion; (H) inflammatory infiltrate; (I) edema; (J) hemorrhage. Data expressed as mean \pm standard mean error $(n=5)$. Mann-Whitney used to calculate statistical significance, ${ }^{*} p<0.05,{ }^{* \star} p<0.01,{ }^{\star \star \star \star} p<0.0001$ vs. ulcerated control. Healthy control, HC; ulcerated control, UC; lansoprazole, L.

$4^{\circ} \mathrm{C}$ with primary antibodies (Santa Cruz Biotechnology, Santa Cruz, CA, United States) against nuclear factor-kappa B-p65, cyclooxygenase-2 (COX-2), and superoxide dismutase (SOD) primary antibodies (Spring-Abcam, MA, United States). Dilution tests (three dilutions) were performed with all antibodies to identify the 1:100, 1:500, and 1:100 dilutions as appropriate, respectively. The slices were washed with $\mathrm{PB}$ and incubated with a streptavidin/HRP-conjugated secondary antibody (Biocare Medical, Concord, CA, United States) for $30 \mathrm{~min}$. Immunoreactivity to the various proteins was visualized with a colorimetric-based detection kit following the protocol provided by the manufacturer (TrekAvidin-HRP Label + Kit from Biocare Medical, Dako, CA, United States). The sections were counterstained with hematoxylin. Known positive controls and negative controls were included in each sample set. Planimetry microscopy (Nikon E200 LED, Morphology Department/UFRN) with a high-power objective (40X) was utilized to score the intensity of cell immunostaining, according to the methodology used by Araújo Júnior et al. (2014).

\section{Statistical Analysis}

All values are reported as the mean \pm standard mean error or as mean \pm standard deviation and were analyzed by one-way analysis of variance (ANOVA) followed by Tukey or Dunnett post-hoc test for multiple comparisons. Nonparametric data (score) are expressed as the median (range) and were analyzed using the Mann-Whitney test. All statistical analyzes were performed using GraphPad 7.0 software (Graph-Pad Software Inc., La Jolla, CA, United States), and the statistical significance was set at $p<0.05$. 


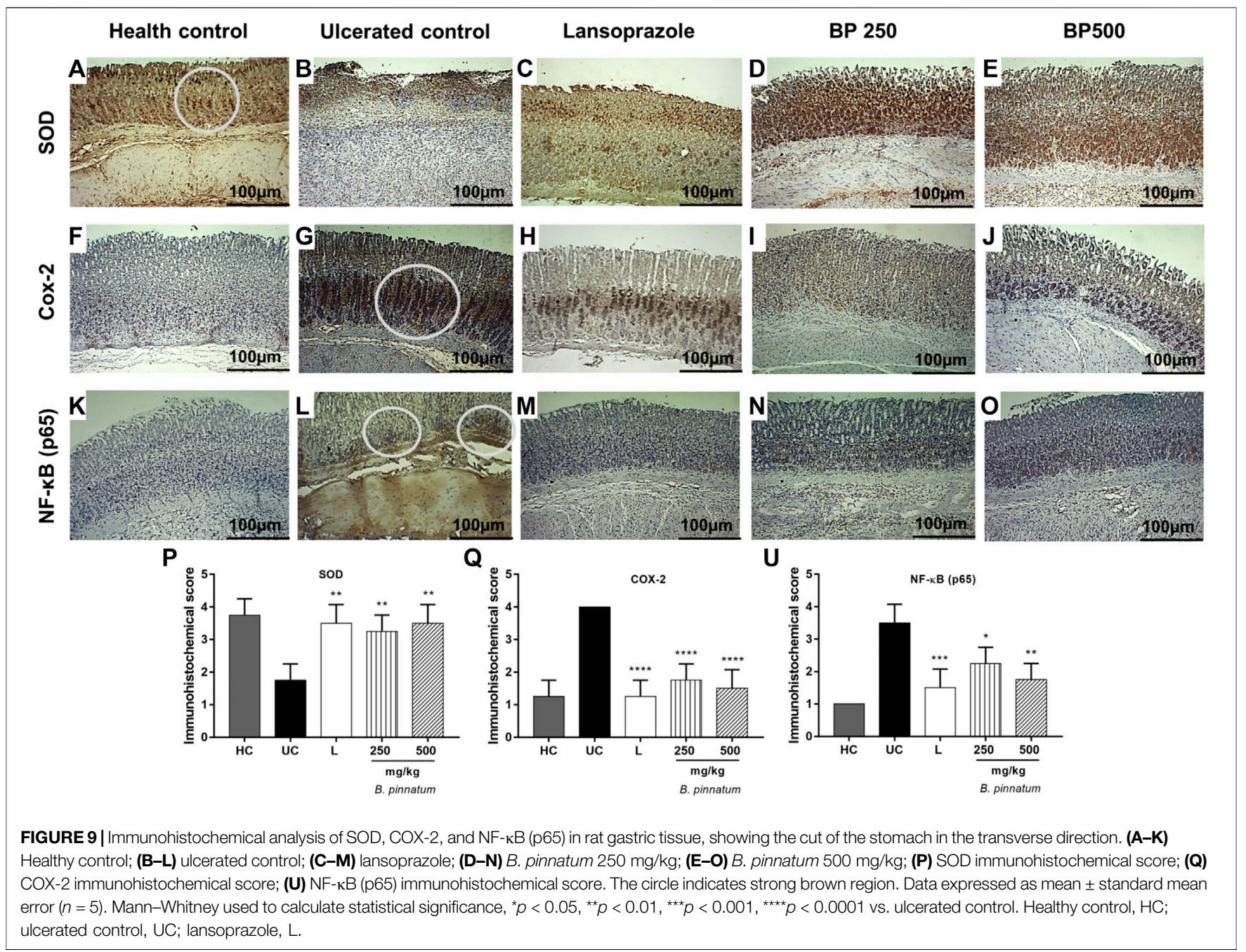

\section{RESULTS}

\section{Quantitative Analyses of Flavonoids Bp1, Bp2, and Bp3 by UFLC-DAD}

A B. pinnatum leaf extract chromatogram is shown in Figure $\mathbf{1}$ with a major peak and other peaks at UV 254 (Figure 1A) and $340 \mathrm{~nm}$ (Figure 1B), corresponding to the flavonoids: Bp1 (Rt $19.20 \pm 0.26)$ (Figure 1C), Bp2 (Rt $19.87 \pm 0.28$ ) (Figure 1D), and Bp3 (Rt $25.58 \pm$ $0.20)$ (Figure 1E). Their UV spectra are similar to those of quercetin (256 and $265 \mathrm{~nm}-\mathrm{II}$ band, and $355 \mathrm{~nm}-\mathrm{I}$ band). The structures of the Bp1, Bp2, and Bp3 flavonoids are shown in Figures $2 \mathrm{~A}-\mathrm{C}$, respectively. Extract peaks were identified by comparing retention times, UV spectra data, and increasing peak areas by co-injection (extract + standard solutions, 1:1, $\mathrm{v} / \mathrm{v})$. The peaks were found to have already been identified and previously described by our research group (Fernandes et al., 2016; Andrade et al., 2020; Fernandes et al., 2021), but this is the first time that the major flavonoids have been quantified and correlated with the pharmacological activity. In a previous study, the major flavonoids identified in $B$. pinnatum by high-performance liquid chromatography coupled with DAD-MS/MS were flavonoids-O-glycosides derived from aglicones eupafolin, quercetin, and kaempferol. In this work, the major flavonoid (Bp1) and two other compounds (Bp2 and Bp3) were quantified as possible analytical markers of this species. The UFLCDAD method for quantifying flavonoids indicated good linearity $(r>0.9997-B p 1 ; \quad r>0.9996-B p 2 ; r>$ $0.9992-\mathrm{Bp} 3)$, specificity, selectivity, precision, robustness, and accuracy (Table 1). The Bp1, Bp2, and Bp3 contents were $33.12 \pm 0.056,3.98 \pm 0.049$, and $4.26 \pm 0.022 \mathrm{mg}$, respectively, per gram of extract (Table 1 ).

\section{IN VIVO STUDIES}

\section{Evaluation of Ulcer Healing Property of Bryophyllum pinnatum Extract Macroscopic Stomach Lesion Assessment}

Our results showed that the $80 \%$ acetic acid instillation in the subserosal layer caused a chronic and severe ulcer with extensive eroded areas in the deep layers of the gastric mucosa (Figure 3B). 
TABLE 3|Effect of pretreatment with Bp1 (2.5, 5, and $10 \mathrm{mg} / \mathrm{kg})$ in the lesion area and percent inhibition in the ethanol-induced model.

\begin{tabular}{lcc} 
Experimental group & Lesion area $(\mathbf{m m})$ & Inhibition percentage (\%) \\
\hline Ulcerated control & $37.57 \pm 3.46$ & - \\
Ranitidine $(50 \mathrm{mg} / \mathrm{kg})$ & $25.83 \pm 5.64^{\star \star}$ & 30.24 \\
Bp1 $(2.5 \mathrm{mg} / \mathrm{kg})$ & $29.86 \pm 3.85$ & 18.65 \\
Bp1 $(5 \mathrm{mg} / \mathrm{kg})$ & $18.86 \pm 4.30^{\star \star \star \star}$ & 48.67 \\
Bp1 $(10 \mathrm{mg} / \mathrm{kg})$ & $36.29 \pm 8.46$ & 0.66 \\
\hline
\end{tabular}

Results expressed as mean \pm standard deviation $(\mathrm{n}=7)$. ANOVA and Dunnett post-test were used to calculate the statistical significance, ${ }^{* *} \mathrm{p}<0.01$ and ${ }^{* * *} \mathrm{p}<0.0001$ vs. gastric lesion control.

TABLE 4 | Effect of pretreatment with Bp1 $(2.5,5$, and $10 \mathrm{mg} / \mathrm{kg})$ in the lesion area and percent inhibition in the indomethacin-induced model.

\begin{tabular}{lcc} 
Experimental group & Lesion area $(\mathbf{m m})$ & Inhibition percentage (\%) \\
\hline Ulcerated control & $7.29 \pm 1.11$ & - \\
Ranitidine $(50 \mathrm{mg} / \mathrm{kg})$ & $4.33 \pm 1.63^{\star \star}$ & 41.43 \\
Bp1 $(2.5 \mathrm{mg} / \mathrm{kg})$ & $5.71 \pm 1.38$ & 22.09 \\
Bp1 $(5 \mathrm{mg} / \mathrm{kg})$ & $3.57 \pm 1.51^{\star \star \star}$ & 51.38 \\
Bp1 $(10 \mathrm{mg} / \mathrm{kg})$ & $4.57 \pm 1.72^{\star \star}$ & 38.39
\end{tabular}

Results expressed as mean \pm standard deviation $(\mathrm{n}=7)$. ANOVA and Dunnett post-test were used to calculate the statistical significance, ${ }^{* *} \mathrm{p}<0.01$ and ${ }^{* * *} \mathrm{p}<0.001$ vs. gastric lesion control.

Treatment with B. pinnatum extract at doses of $125 \mathrm{mg} / \mathrm{kg}(p<$ $0.05), 250 \mathrm{mg} / \mathrm{kg}(p<0.0001)$, and $500 \mathrm{mg} / \mathrm{kg}(p<0.0001)$ and with lansoprazole at $30 \mathrm{mg} / \mathrm{kg}(p<0.0001)$ significantly reduced the ulcerated area and ulceration index when compared to the ulcerated control group (Figure 3; Table 2), showing that the treatment with $B$. pinnatum leaf extract could reduce the lesion area $(\mathrm{mm})$ and consequently stimulate the healing process of chronic ulcers provoked by $80 \%$ acetic acid.

\section{Effect of Bryophyllum pinnatum Leaf Extract on Nonprotein Sulfhydryls Levels}

In Figure 4, it is observed that the GSH levels in the healthy gastric tissue are elevated when compared with the ulcerated control group; this occurs because the $80 \%$ acetic acid instillation in the subserosal layer resulted in a decrease in the basal GSH levels. Treatment with $B$. pinnatum leaf extract at doses of $250 \mathrm{mg} / \mathrm{kg}(p<0.01)$ and $500 \mathrm{mg} / \mathrm{kg}(p<0.001)$ could increase the GSH levels in the gastric tissue when compared with the ulcerated control group (Figure 4). In addition, the treatment with the drug lansoprazole $30 \mathrm{mg} / \mathrm{kg}(p<0.0001)$ also significantly increase the GSH levels in the gastric tissue when compared to the ulcerated control group (Figure 4).

The $80 \%$ acetic acid instillation in the subserosal layer resulted in an increase in MDA levels in the gastric tissue of the ulcerated control group (Figure 5). Treatment with B. pinnatum leaf extract at doses of $250 \mathrm{mg} / \mathrm{kg}(p<0.0001)$ and $500 \mathrm{mg} / \mathrm{kg}(p<$ 0.0001 ) could significantly reduce the MDA levels when compared to the ulcerated control group (Figure 5). Treatment with the drug lansoprazole $30 \mathrm{mg} / \mathrm{kg}(p<0.0001)$ also significantly reduced the MDA levels in the gastric tissue when compared to the ulcerated control group (Figure 5).

\section{Effect of Bryophyllum pinnatum Leaf Extract on Myeloperoxidase Activity}

Figure 6 shows that the $80 \%$ acetic acid instillation in the subserosal layer provoked an increase in the MPO enzyme activity. Treatment with $B$. pinnatum leaf extract at doses of $125 \mathrm{mg} / \mathrm{kg}(p<0.001), 250 \mathrm{mg} / \mathrm{kg}(p<0.0001)$, and $500 \mathrm{mg} / \mathrm{kg}$ $(p<0.0001)$ significantly reduced the MPO enzyme activity compared to the ulcerated control group (Figure 6). The treatment with lansoprazole at $30 \mathrm{mg} / \mathrm{kg}(p<0.0001)$ significantly reduced the MPO enzyme activity in this assay.

\section{Effect of Bryophyllum pinnatum Leaf Extract on Interleukin-1 $\beta$, Tumor Necrosis Factor- $\alpha$, and Interleukin 10 Levels}

The $80 \%$ acetic acid instillation in the subserosal layer elevated IL$1 \beta$ (Figure 7A) and TNF- $\alpha$ (Figure 7B) levels in the gastric tissue. Treatment with $B$. pinnatum leaf extract at doses of $250 \mathrm{mg} / \mathrm{kg}$ $(p<0.001)$ and $500 \mathrm{mg} / \mathrm{kg}(p<0.0001)$ could significantly reduce IL- $1 \beta$ when compared to the ulcerated control group (Figure 7A). It was also observed that treatment with $B$. pinnatum leaf extract at doses of $125 \mathrm{mg} / \mathrm{kg}(p<0.05), 250 \mathrm{mg} / \mathrm{kg}(p<0.05)$, and $500 \mathrm{mg} / \mathrm{kg}(p<0.05)$ could reduce the TNF- $\alpha$ levels in the gastric tissue (Figure 7B). Lansoprazole treatment at a dose of $30 \mathrm{mg} / \mathrm{kg}$ could also significantly reduce the IL-1 $\beta(p<0.0001)$ and TNF- $\alpha$

\begin{tabular}{|c|c|c|c|c|c|c|}
\hline Inflammatory markers & $\begin{array}{l}\text { B. pinnatum } \\
(125 \mathrm{mg} / \mathrm{kg})\end{array}$ & $\begin{array}{l}\text { B. pinnatum } \\
(250 \mathrm{mg} / \mathrm{kg})\end{array}$ & $\begin{array}{l}\text { B. pinnatum } \\
(500 \mathrm{mg} / \mathrm{kg})\end{array}$ & Bp1 (2.5 mg/kg) & Bp1 (5 mg/kg) & Bp1 10 (mg/kg) \\
\hline GSH & N.S & $\uparrow$ & $\uparrow$ & N.S & $\uparrow$ & N.S \\
\hline MDA & N.S & $\downarrow$ & $\downarrow$ & N.S & $\downarrow$ & N.S \\
\hline SOD & N.S & $\uparrow$ & $\uparrow$ & - & - & - \\
\hline MPO & N.S & $\downarrow$ & $\downarrow$ & N.S & $\downarrow$ & N.S \\
\hline $\mathrm{IL}-1 \beta$ & N.S & $\downarrow$ & $\downarrow$ & N.S & $\downarrow$ & $\downarrow$ \\
\hline TNF- $\alpha$ & $\downarrow$ & $\downarrow$ & $\downarrow$ & N.S & $\downarrow$ & $\downarrow$ \\
\hline IL-10 & $\uparrow$ & $\uparrow$ & $\uparrow$ & N.S & $\uparrow$ & N.S \\
\hline$N F-\kappa B(p 65)$ & N.S & $\downarrow$ & $\downarrow$ & - & - & - \\
\hline COX-2 & N.S & $\downarrow$ & $\downarrow$ & - & - & - \\
\hline
\end{tabular}

N.S, not statically significant. 
A

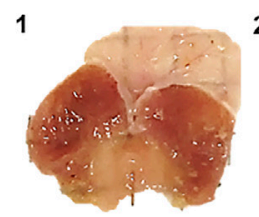

2

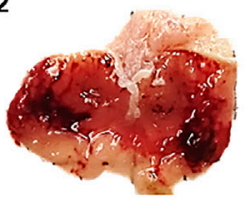

5

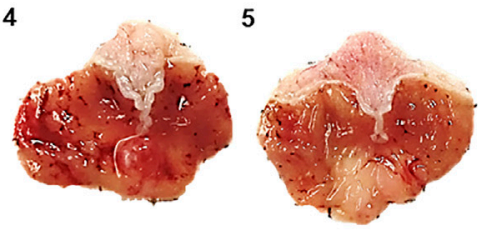

4

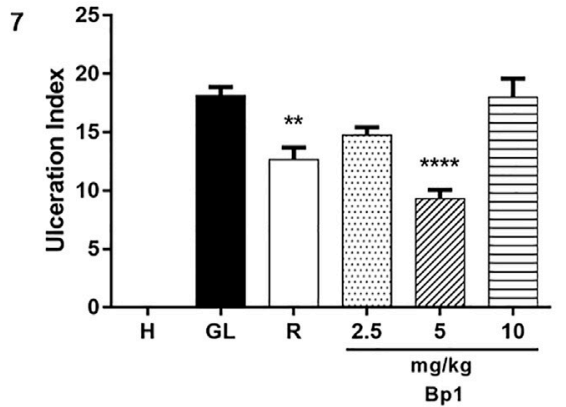

B

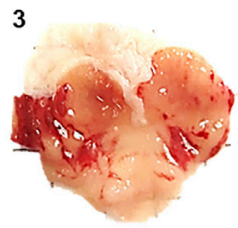

6

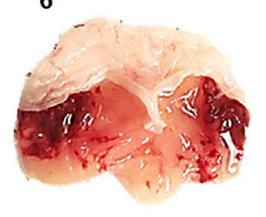

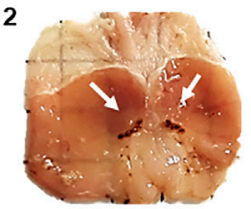

5
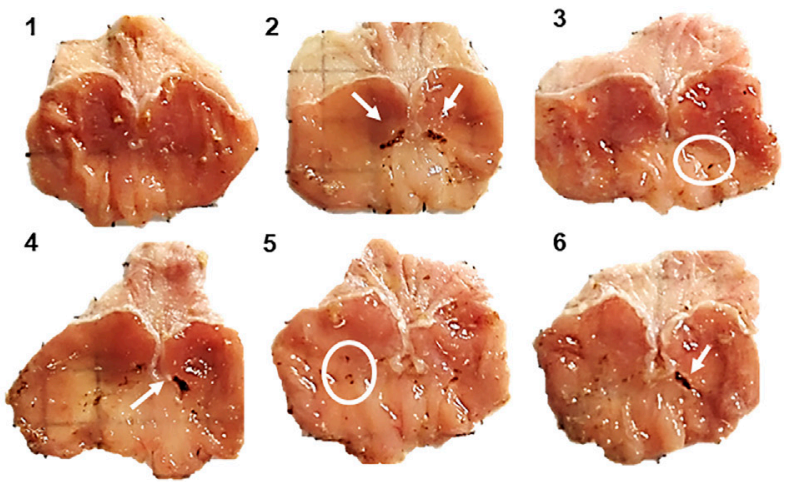

6

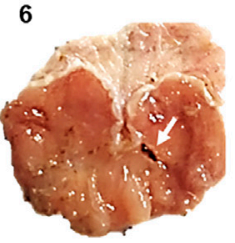

7

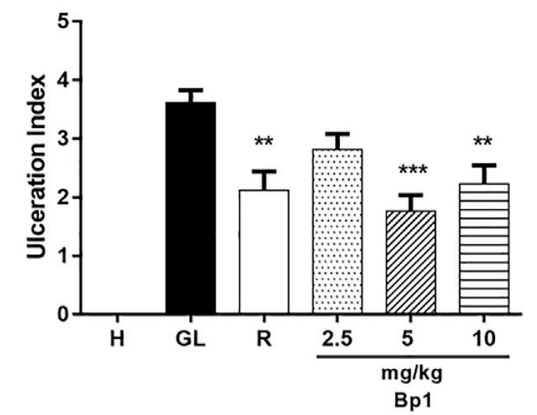

FIGURE 10 | Effect of pretreatment with Bp1 (2.5, 5, and $10 \mathrm{mg} / \mathrm{kg})$ on the macroscopic appearance of the gastric mucosa in ethanol-induced (A) and indomethacin-induced (B) gastric mucosal lesions in mice. (A) Ethanol-induced: 1) healthy; 2) gastric lesion control; 3) ranitidine, 50 mg/kg; 4) Bp1, 2.5 mg/kg; 5) Bp1, $5 \mathrm{mg} / \mathrm{kg}$; 6) Bp1, $10 \mathrm{mg} / \mathrm{kg}$; 7) ulceration index. (B) Indomethacin induced: 1) healthy; 2) gastric lesion control; 3) ranitidine, 50 mg/kg; 4) Bp1, 2.5 mg/kg; 5) Bp1, $5 \mathrm{mg} / \mathrm{kg}$; 6) Bp1, $10 \mathrm{mg} / \mathrm{kg}$; 7) ulceration index. Results are expressed as mean \pm standard mean error $(n=7)$. ANOVA and Dunnett post-test were used to calculate the statistical significance, ${ }^{\star \star} p<0.01$, ${ }^{\star \star \star} p<0.001$, and ${ }^{\star \star \star \star} p<0.0001$ vs. gastric lesion control. Healthy, H; gastric lesion control, GL; ranitidine (50 mg/kg), R.

$(p<0.05)$ levels in the gastric mucosa (Figures 7A,B, respectively). Figure $7 \mathrm{C}$ shows that the $80 \%$ acetic acid instillation in the subserosal layer reduced the IL-10 levels in the ulcerated control. The treatment with $B$. pinnatum at doses of $125 \mathrm{mg} / \mathrm{kg}(p<0.05), 250 \mathrm{mg} / \mathrm{kg}(p<0.01)$, and $500 \mathrm{mg} / \mathrm{kg}(p<$ $0.0001)$ significantly increased the IL-10 levels compared to the ulcerated control group (Figure 7C). Lansoprazole treatment at a dose of $30 \mathrm{mg} / \mathrm{kg}(p<0.0001)$ could significantly increase the IL10 levels in the gastric tissue (Figure 7C).

\section{Histopathology}

Figure $8 \mathbf{A}$ that pathological changes were not observed in the healthy control group stomachs, as indexed by a semiquantitative score system. However, the $80 \%$ acetic acid instillation in the subserosal layer provoked the presence of erosions in the superficial layer and in the deeper layers of the gastric mucosa (Figure 8B). The presence of interruption of the superficial epithelium and also the deeper layers, in addition to inflammatory infiltrate, edema, and hemorrhage, were observed in the ulcerated control group (Figure 8B). Treatment with $B$. pinnatum leaf extract at a dose of $125 \mathrm{mg} / \mathrm{kg}$ showed necrotic lesion, hemorrhage points, and intense inflammatory infiltrate (Figure 8D). Treatment with B. pinnatum leaf extract at doses of $250 \mathrm{mg} / \mathrm{kg}$ (Figure 8E) and $500 \mathrm{mg} / \mathrm{kg}$ (Figure 8F) and with lansoprazole at $30 \mathrm{mg} / \mathrm{kg}$ (Figure 8C) showed an ulcer healing process with a slight interruption of the superficial epithelium and a slight presence of edema and leukocyte infiltrate. Hemorrhaging was not observed in the treatment with $B$. pinnatum leaf extract at a dose of $500 \mathrm{mg} / \mathrm{kg}$ and with lansoprazole $30 \mathrm{mg} / \mathrm{kg}$. Treatment with B. pinnatum leaf extract at doses of $250 \mathrm{mg} / \mathrm{kg}$ (Figure 8E) and $500 \mathrm{mg} / \mathrm{kg}$ (Figure 8F) and with lansoprazole at $30 \mathrm{mg} / \mathrm{kg}$ (Figure 8C) could preserve the mucosal and submucosal structural architecture (crypts and gastric glands) when compared to the ulcerated control group.

\section{Immunohistochemical Staining of Superoxide Dismutase, Cyclooxygenase-2, and Nuclear Factor-Kappa B-p65}

Immunohistochemistry analysis for SOD revealed a strong brown (circle) in gastric tissue cells observed in the healthy control group (Figure 9A) and a weak brown in the ulcerated control group (Figure 9B). Treatment with $B$. pinnatum leaf extract at doses of $250 \mathrm{mg} / \mathrm{kg}(p<0.01)$ and $500 \mathrm{mg} / \mathrm{kg}(p<0.01)$ and lansoprazole upregulated $(p<0.01)$ the expression of this marker in the gastric tissue when compared with the ulcerated gastric control (Figures 9C-E, respectively).

Figures 9G,L show that $80 \%$ acetic acid instillation in the subserosal layer resulted in upregulated expression of the 

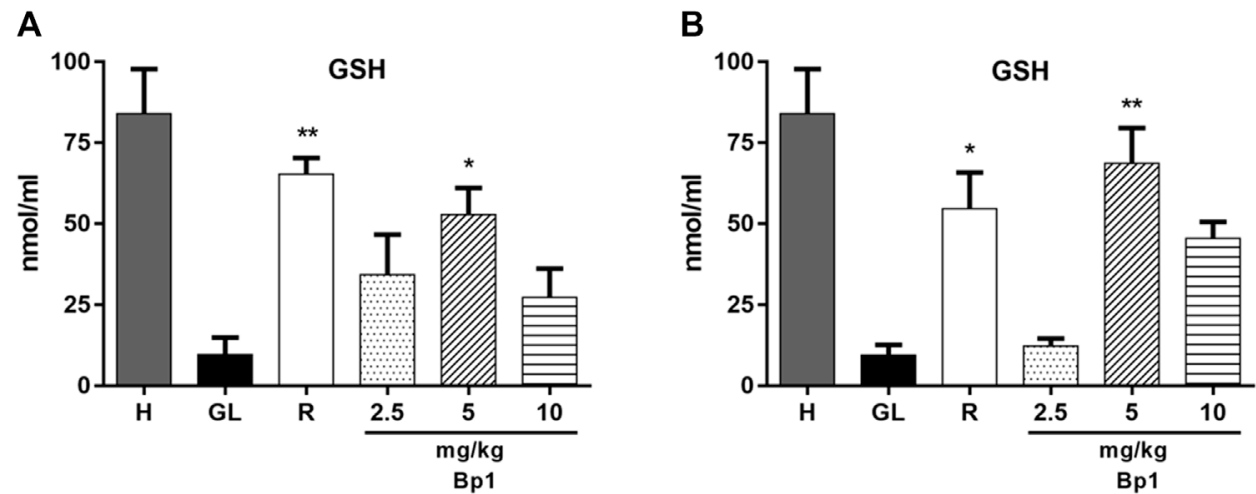

FIGURE 11 | Effect of pretreatment with Bp1 (2.5, 5, and $10 \mathrm{mg} / \mathrm{kg})$ on GSH levels in the gastric mucosa homogenate of lesions in mice (A) ethanol-induced and (B) indomethacin-induced. Results expressed as mean \pm standard mean error $(n=7)$. ANOVA and Tukey post-test were used to calculate the statistical significance, ${ }^{\star} p<$ 0.05 and ${ }^{* *} p<0.01$ vs. gastric lesion control. Healthy, $\mathrm{H}$; gastric lesion control, GL; ranitidine $(50 \mathrm{mg} / \mathrm{kg}), \mathrm{R}$.
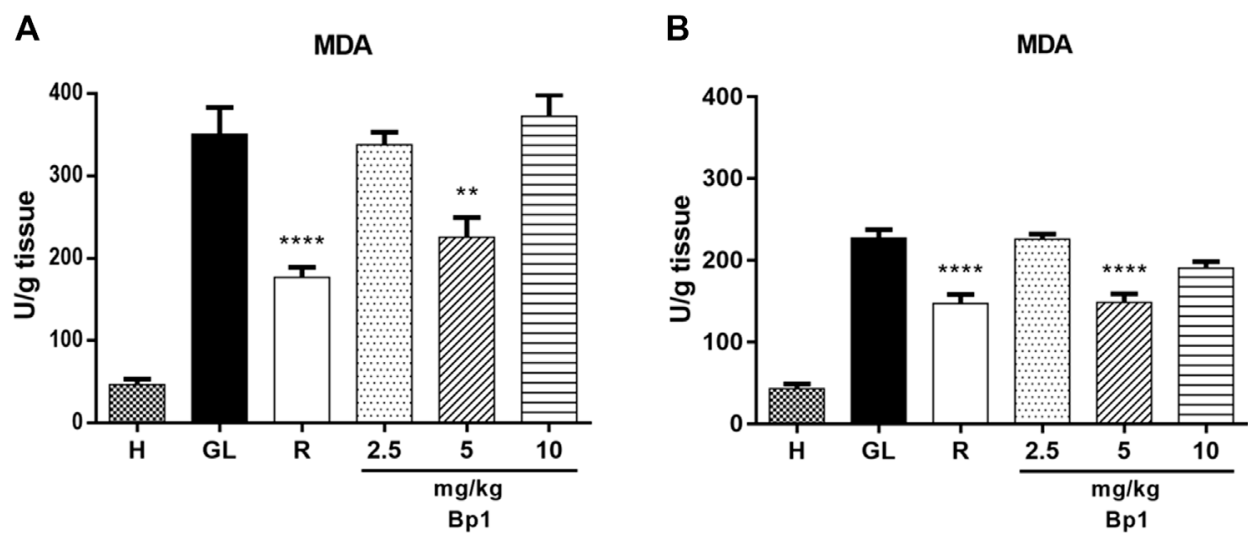

FIGURE 12 | Effect of pretreatment with Bp1 (2.5, 5, and $10 \mathrm{mg} / \mathrm{kg})$ on MDA levels in the gastric mucosa homogenate of lesions in mice (A) ethanol-induced and (B) indomethacin-induced. Results expressed as mean \pm standard mean error $(n=7)$. ANOVA and Tukey post-test were used to calculate the statistical significance, ${ }^{* *} p<0.01$ and ${ }^{* \star * *} p<0.0001$ vs. gastric lesion control. Healthy, H; gastric lesion control, GL; ranitidine $(50 \mathrm{mg} / \mathrm{kg}), \mathrm{R}$.
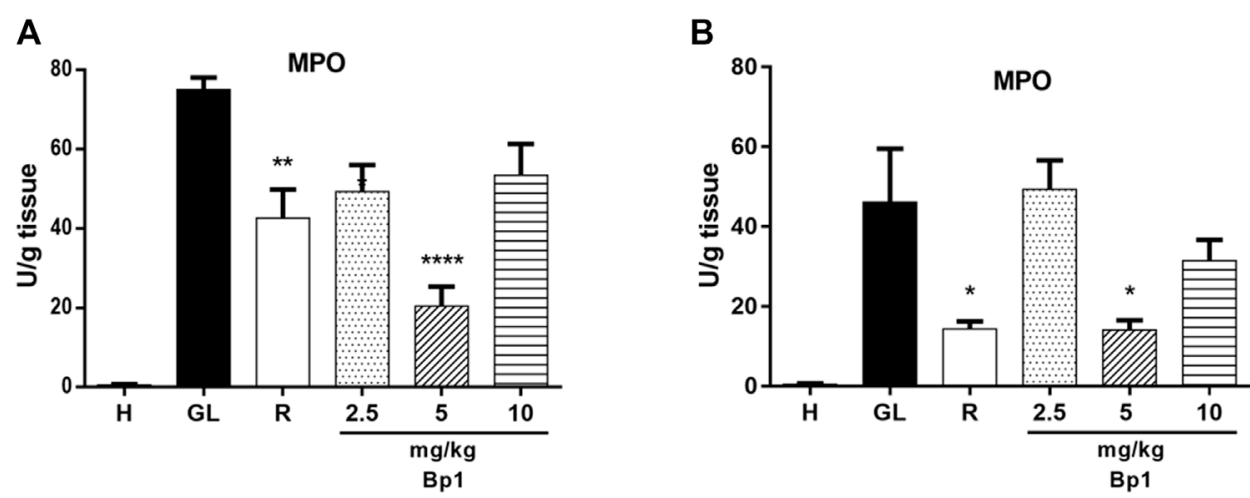

FIGURE 13 | Effect of pretreatment with Bp1 (2.5, 5, and $10 \mathrm{mg} / \mathrm{kg})$ on MPO enzyme activity in the gastric mucosa homogenate of lesions in mice (A) ethanolinduced and (B) indomethacin-induced. Results expressed as mean \pm standard mean error $(n=7)$. ANOVA and Tukey post-test were used to calculate the statistical significance, ${ }^{\star} p<0.05,{ }^{\star \star} p<0.01$, and ${ }^{\star \star \star \star} p<0.0001$ vs. gastric lesion control. Healthy, H; gastric lesion control, GL; ranitidine (50 mg/kg), R.

COX-2 and NF-kB (p65) in the gastric tissue of the ulcerated control group, observed as strong brown (circle), while treatment with $B$. pinnatum leaf extract at doses of
$250 \mathrm{mg} / \mathrm{kg}$ ( $p<0.0001$ and $p<0.05$, respectively, for these markers-Figures 9I,N) and $500 \mathrm{mg} / \mathrm{kg}(p<0.0001$ and $p<$ 0.01, respectively, for these markers-Figures 9J,O) 

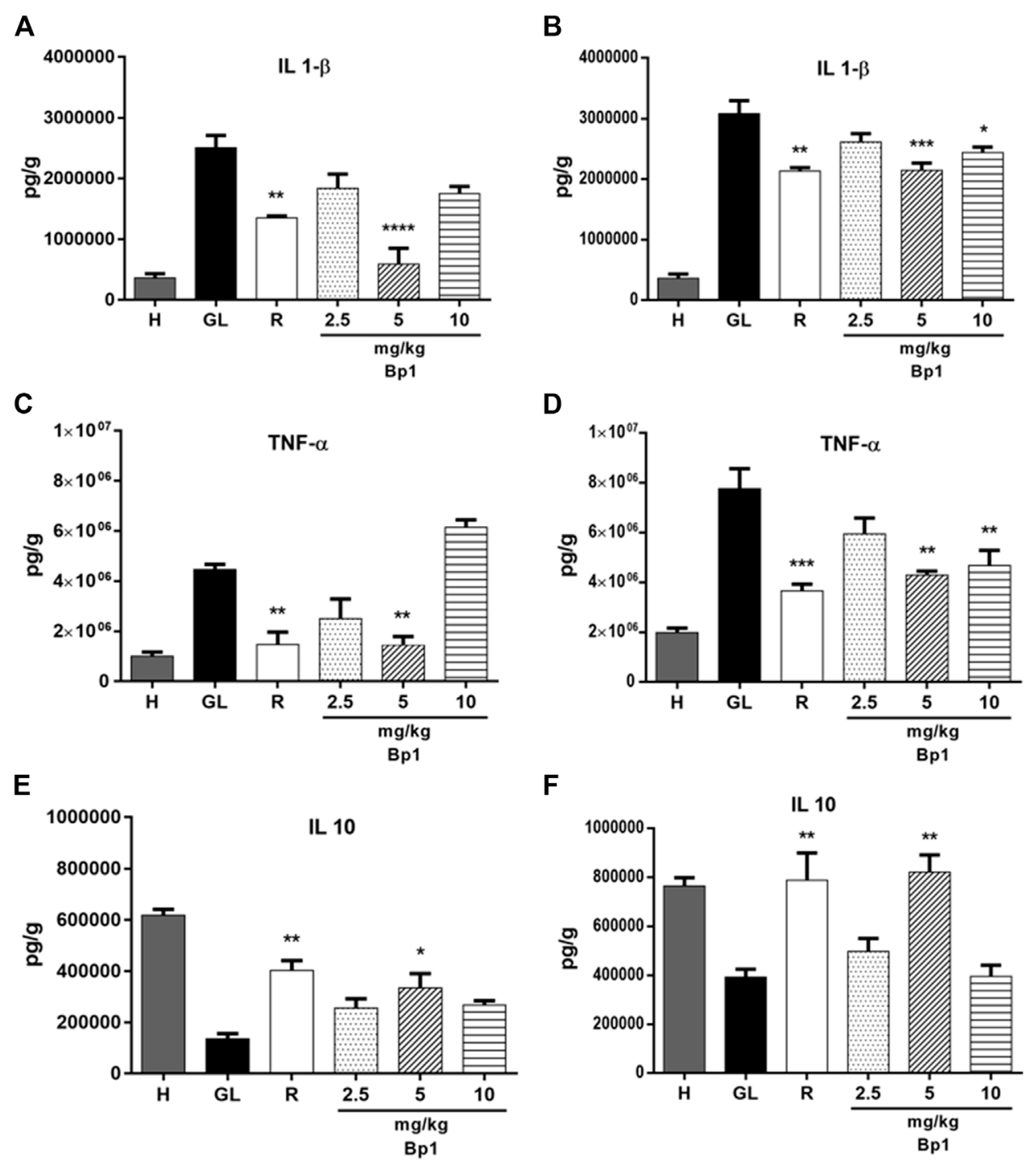

FIGURE 14 | Effect of pretreatment with Bp1 (2.5, 5, and $10 \mathrm{mg} / \mathrm{kg})$ on IL-1 $\beta$, TNF- $\alpha$, and IL-10 levels in the gastric mucosa homogenate of lesions in mice (A-E) ethanol-induced and (B-F) indomethacin-induced. Results expressed as mean \pm standard mean error $(n=7)$. ANOVA and Tukey post-test were used to calculate the statistical significance, ${ }^{\star} p<0.05,{ }^{\star \star} p<0.01,{ }^{\star \star \star} p<0.001$, and ${ }^{* \star \star *} p<0.0001$ vs. gastric lesion control. Healthy, H; gastric lesion control, GL; ranitidine (50 mg/kg), R.

downregulated the expression, observed as weak brown. The treatment with lansoprazole $(p<0.0001$ and $p<0.001$, respectively-Figures $\mathbf{9 H}, \mathbf{M})$ also downregulated the expression of these markers, observed as weak brown.

\section{Investigating the Gastroprotective Activity of Quercetin 3-O- $\alpha$-L-Arabinopyranosyl -(1 $\rightarrow 2)-O-\alpha-L-R h a m n o p y r a n o s i d e ~(B p 1)$ in Gastric Lesions Models Macroscopic Stomach Lesion Assessment}

Figure 10A2 shows that the oral administration of absolute ethanol $(0.5 \mathrm{ml} / \mathrm{kg})$ provoked intense lesions in the gastric mucosa with hemorrhagic erosions in the gastric lesion control. The pretreatment with quercetin 3-O- $\alpha$-L-arabinopyranosyl-( $1 \rightarrow 2)$ $O-\alpha$-L-rhamnopyranoside $(\mathrm{Bp} 1)$ at a dose of $5 \mathrm{mg} / \mathrm{kg}(p<$
$0.0001)$ and with ranitidine at $50 \mathrm{mg} / \mathrm{kg}(p<0.01)$ significantly reduced the lesions and the ulceration index when compared to the gastric lesion control (Figure 10A 0.5); Table 3 shows that the inhibition percentages and that the pretreatment with quercetin 3 $O$ - $\alpha$-L-arabinopyranosyl- $(1 \rightarrow 2)-O-\alpha$-L-rhamnopyranoside $\quad(B p 1)$ and ranitidine could protect the gastric mucosa from developing lesions induced by ethanol.

Oral administration of indomethacin $(40 \mathrm{mg} / \mathrm{kg})$ caused gastric lesion in the gastric lesion control (Figure 10B2). Pretreatment with quercetin 3-O- $\alpha$-L-arabinopyranosyl- $(1 \rightarrow 2)$ $O$ - $\alpha$-L-rhamnopyranoside $(\mathrm{Bp} 1)$ at doses of $5 \mathrm{mg} / \mathrm{kg}(p<0.001)$ and $10 \mathrm{mg} / \mathrm{kg}(p<0.01)$ and with ranitidine at $50 \mathrm{mg} / \mathrm{kg}(p<$ 0.01 ) could significantly reduce the ulceration index when compared to the gastric lesion control. It is possible to observe the inhibition percentages in Table 4, and that the pretreatment with quercetin 3-O-a-L-arabinopyranosyl-( $1 \rightarrow 2)$ - 
A

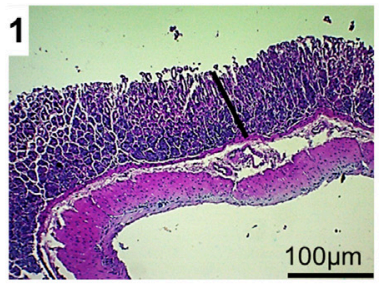

3

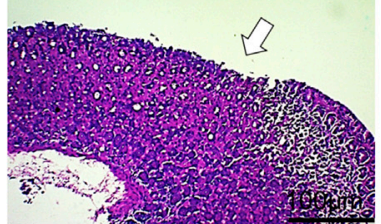

5

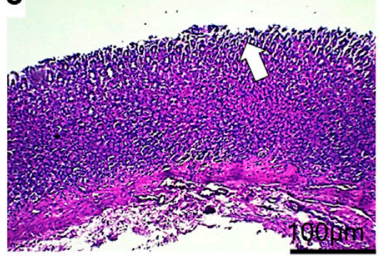

7

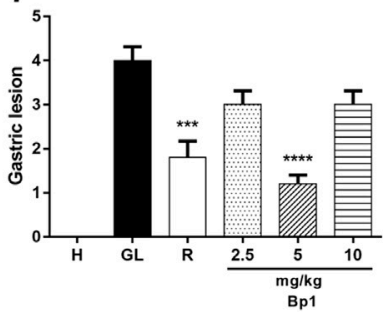

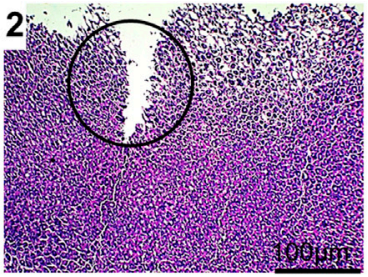
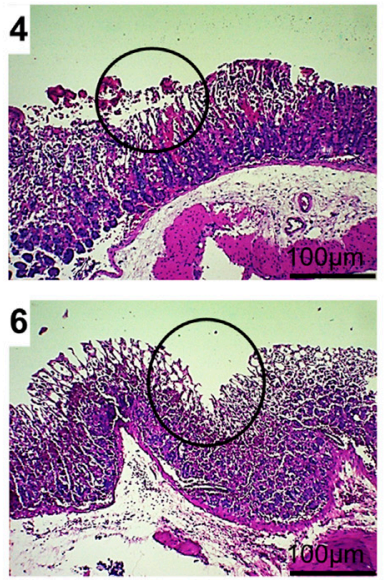

8

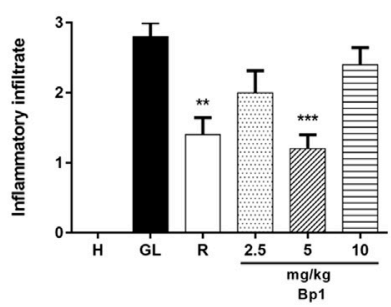

B
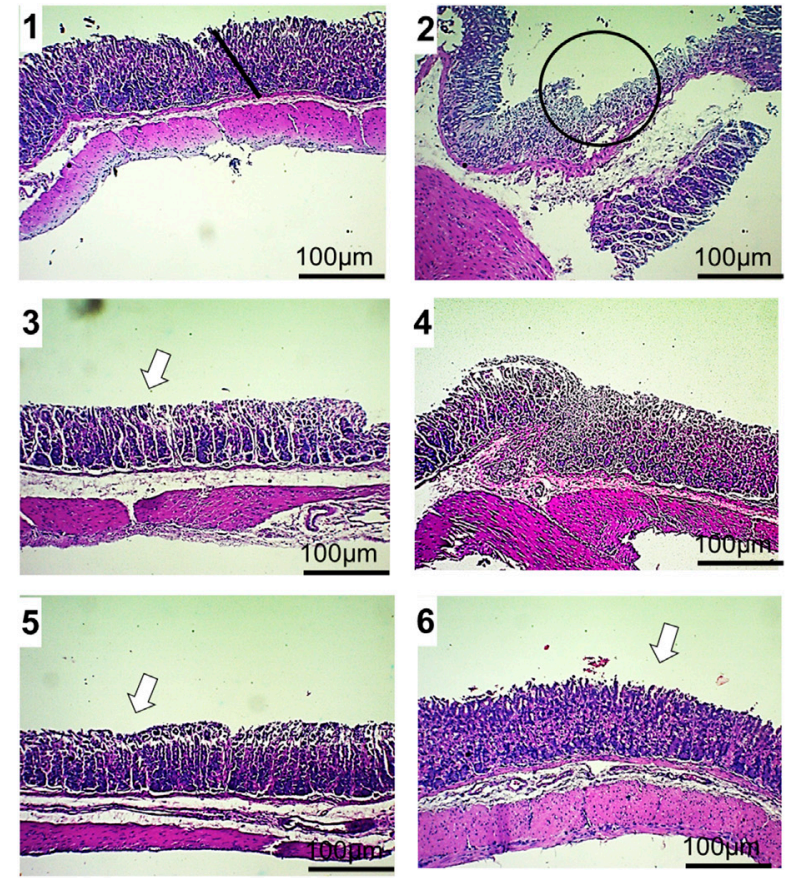

7

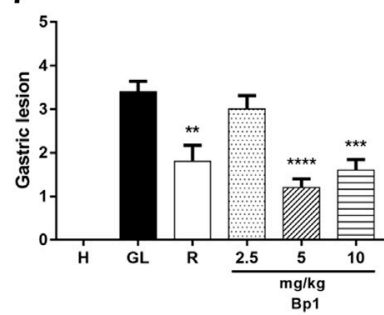

8

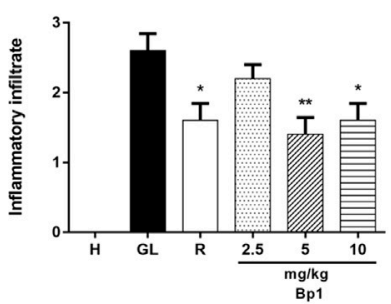

FIGURE 15 | Effect of pre-treatment with Bp1 (2.5, 5, and $10 \mathrm{mg} / \mathrm{kg})$ on the histology of ethanol-induced (A) and indomethacin-induced (B) gastric mucosal lesions in mice. Histopathological characteristics of the gastric tissue of rats, showing the cut of the stomach in the transverse direction. (A) Ethanol-induced: (1) Healthy; (2) Gastric lesion control; (3) Ranitidine, 50 mg/kg; (4) Bp1 2.5 mg/kg; (5) Bp1 5 mg/kg; (6) Bp1 10 mg/kg; (7) Gastric lesion score; (8) Inflammatory infiltrate score. (B) Indomethacin-induced: (1) Healthy; (2) Gastric lesion control; (3) Ranitidine, 50 mg/kg; (4) Bp1 2.5 mg/kg; (5) Bp1 5 mg/kg; (6) Bp1 10 mg/kg; (7) Gastric lesion score; (8) Inflammatory infiltrate. The bar indicates gastric mucosa without changes; Circle: severe lesion with distraction of the surface epithelium; White arrow: recovered mucosa. Results expressed as mean \pm standard mean error $(n=7)$. Mann-Whitney used to calculate statistical significance, ${ }^{*} p<0.05,{ }^{\star \star} p<0.01,{ }^{\star \star *} p<$ 0.001 , and ${ }^{\star \star \star \star} \mathrm{p}<0.0001$ vs. gastric lesion control. Healthy, H; Gastric lesion control, GL; Ranitidine $(50 \mathrm{mg} / \mathrm{kg})$, R. gastric mucosal damage in rats.

O- $\alpha$-L-rhamnopyranoside (Bp1) and ranitidine could prevent the gastric mucosa from developing lesions; the results for this are expressed as mean \pm standard deviation, $(n=7)$. ANOVA and Dunnett post-test were used to calculate the statistical significance, ${ }^{* *} p<0.01$ and ${ }^{* * *} p<0.001$ vs. gastric lesion control.

\section{Effect of Quercetin 3-O- $\alpha$-L-Arabinopyranosyl

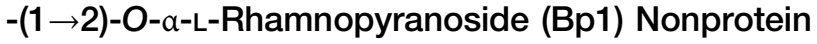 Sulfhydryls Levels}

Figures $11 \mathrm{~A}, \mathbf{B}$ show that the oral administration of ethanol $(0.5 \mathrm{ml} / \mathrm{kg})$ and indomethacin $(40 \mathrm{mg} / \mathrm{kg})$ in mice provoked a decrease in GSH levels in the gastric tissue. The pretreatment with quercetin $3-O-\alpha$-L-arabinopyranosyl-( $(1 \rightarrow 2)$ $O$ - $\alpha$-L-rhamnopyranoside (Bp1) at a dose of $5 \mathrm{mg} / \mathrm{kg}$ significantly elevated the GSH levels in the gastric tissue in the ethanol- $(p<0.5)$
(Figure 11A) and indomethacin-induced $(p<0.01)$ (Figure 11B) assays when compared with the gastric lesion control. The pretreatment with ranitidine $(50 \mathrm{mg} / \mathrm{kg})$ also significantly elevated the GSH levels in the gastric tissue in the ethanol$(p<0.01)$ (Figure 11A) and indomethacin-induced $(p<0.5)$ (Figure 11B) assays when compared with the gastric lesion control.

The oral administration of ethanol $(0.5 \mathrm{ml} / \mathrm{kg})$ and indomethacin $(40 \mathrm{mg} / \mathrm{kg})$ in mice provoked an increase in MDA levels in the gastric tissue (Figures 12A,B). The pretreatment with quercetin $3-O-\alpha$-L-arabinopyranosyl- $(1 \rightarrow 2)$ $O$ - $\alpha$-L-rhamnopyranoside (Bp1) at a dose of $5 \mathrm{mg} / \mathrm{kg}(p<0.01)$ significantly reduced the MDA levels in the gastric tissue when compared to the gastric lesion control in the ethanol-induced assay (Figure 12A). The pretreatment with quercetin 3-O$\alpha$-L-arabinopyranosyl-( $1 \rightarrow 2)$-O- $\alpha$-L-rhamnopyranoside $(\mathrm{Bp} 1)$ at 
a dose of $5 \mathrm{mg} / \mathrm{kg}(p<0.0001)$ also significantly reduced the MDA levels in the gastric mucosa in the indomethacin-induced assay (Figure 12B). The pretreatment with ranitidine $50 \mathrm{mg} / \mathrm{kg}$ significantly reduced the MDA levels in the gastric tissue in the ethanol- $(p<0.0001)$ and indomethacin-induced $(p<$ 0.0001) assays (Figures 12A,B, respectively).

\section{Effect of Quercetin 3-O- $\alpha-L-A r a b i n o p y r a n o s y l$ -(1 $\rightarrow 2)-O-\alpha-L-R h a m n o p y r a n o s i d e ~(B p 1)$ on Myeloperoxidase Activity}

Figures 13A,B show that the oral administration of ethanol $(0.5 \mathrm{ml} / \mathrm{kg})$ and indomethacin $(40 \mathrm{mg} / \mathrm{kg})$ in mice caused an increase in the MPO enzyme activity in the gastric tissue. The pretreatment with quercetin 3-O- $\alpha$-L-arabinopyranosyl$(1 \rightarrow 2)$-O- $\alpha$-L-rhamnopyranoside (Bp1) at a dose of $5 \mathrm{mg} / \mathrm{kg}$ $(p<0.0001)$ significantly reduced the MPO enzyme activity in the gastric tissue when compared to the gastric lesion control in the ethanol-induced assay (Figure 13A). In addition, pretreatment with quercetin 3-O- $a$-L-arabinopyranosyl- $(1 \rightarrow 2)$ $O-\alpha$-L-rhamnopyranoside (Bp1) at a dose of $5 \mathrm{mg} / \mathrm{kg}(p<0.05)$ also significantly reduced the MPO enzyme activity in the gastric mucosa when compared to the gastric lesion control in the indomethacin-induced assay (Figure 13B). The pretreatment with ranitidine $50 \mathrm{mg} / \mathrm{kg}$ significantly reduced the MPO enzyme activity in the gastric mucosa in the ethanol- $(p<0.01)$ and indomethacin-induced $(p<0.05)$ assays (Figures 13A,B, respectively).

\section{Effect of Quercetin 3-O- $\alpha$-L-Arabinopyranosyl -(1 $\rightarrow 2)-O-\alpha-L-R h a m n o p y r a n o s i d e ~(B p 1)$ Pretreatment on Interleukin-1 $\beta$, Tumor Necrosis Factor- $\alpha$, and IL-10 Levels}

The oral administration of ethanol $(0.5 \mathrm{ml} / \mathrm{kg})$ and indomethacin $(40 \mathrm{mg} / \mathrm{kg})$ in mice elevated IL- $1 \beta$ and TNF- $\alpha$ levels in the gastric tissue (Figures 14A-D). The pretreatment with $\mathrm{Bp} 1$ at a dose of $5 \mathrm{mg} / \mathrm{kg}$ significantly reduced the IL- $1 \beta(p<0.0001)$ and TNF- $\alpha$ $(p<0.01)$ levels in the gastric mucosa when compared to the gastric lesion control in the ethanol-induced assay (Figures $14 \mathrm{~A}, \mathrm{C}$, respectively). In addition, the pretreatment with $\mathrm{Bp} 1$ at a dose of $5 \mathrm{mg} / \mathrm{kg}$ significantly reduced the IL- $1 \beta(p<0.001)$ and TNF- $\alpha(p<0.01)$ levels and at a dose of $10 \mathrm{mg} / \mathrm{kg}$ also significantly reduced the IL-1 $\beta(p<0.05)$ and TNF- $\alpha(p<$ 0.01 ) levels in the gastric tissue when compared to the gastric lesion control in the indomethacin-induced assay (Figures 14B,D, respectively). The pretreatment with ranitidine at $50 \mathrm{mg} / \mathrm{kg}$ significantly reduced the IL- $1 \beta(p<0.01$ in both models) and TNF- $\alpha(p<0.1$ in the ethanol-induced assay and $p<0.001$ in the indomethacin-induced assay) levels in the gastric tissue when compared to the gastric lesion control.

The oral administration of ethanol $(0.5 \mathrm{ml} / \mathrm{kg})$ and indomethacin $(40 \mathrm{mg} / \mathrm{kg})$ also reduced the IL-10 levels in the gastric tissue (Figures 14E,F). Pretreatment with Bp1 at a dose of $5 \mathrm{mg} / \mathrm{kg}$ significantly elevated the IL-10 levels in the gastric tissue when compared to the gastric lesion control in the ethanol- $(p<$ $0.05)$ and indomethacin-induced $(p<0.01)$ assays (Figures 14E,F, respectively). The pretreatment with ranitidine at a dose of $50 \mathrm{mg} / \mathrm{kg}$ also significantly elevated the IL-10 levels in the gastric tissue when compared to the gastric lesion control in the ethanol- $(p<0.01)$ and indomethacin-induced $(p<0.01)$ assays (Figures 14E,F, respectively).

\section{Histopathology}

According to the histopathology assay, the Healthy Group showed intact mucosa without changes (Figures 15A1,B1). However, the oral administration of ethanol and indomethacin provoked a severe lesion in the gastric mucosa with the presence of extensive edema and leukocyte infiltration in the mucosa and submucosa layers (Figures $15 \mathrm{~A} 2, \mathbf{B} 2)$. The pretreatment with $3-O-\alpha-\mathrm{L}$-arabinopyranosyl- $(1 \rightarrow 2)$ $O-\alpha$-L-rhamnopyranoside (Bp1) at doses of 2.5 and $10 \mathrm{mg} / \mathrm{kg}$ showed severe lesions in the mucosa with edema and leukocyte infiltration in the ethanol-gastric lesion model (Figures 15A4,A6), while the pretreatment with BP1 at a dose of $5 \mathrm{mg} / \mathrm{kg}$ and with ranitidine at $50 \mathrm{mg} / \mathrm{kg}$ reduced the severity of the lesions, presenting a slight interruption of the superficial epithelium with submucosal edema and minimal leukocyte infiltration (Figures 15A3,A5). Pretreatment with Bp1 at a dose of $2.5 \mathrm{mg} / \mathrm{kg}$ showed severe injuries in the gastric mucosa with edema and leukocyte infiltration in the indomethacin gastric lesion model (Figures 15B4), while the pretreatment with $\mathrm{Bp} 1$ at doses of 5 and $10 \mathrm{mg} / \mathrm{kg}$ and with ranitidine at a dose of $50 \mathrm{mg} / \mathrm{kg}$ improved lesion severity, presenting a slight interruption of the superficial epithelium with submucosal edema and minimal leukocyte infiltration (Figures 15B3-B6, respectively).

To summarize the results obtained in this work, pretreatment with quercetin 3-O- $\alpha$-L-arabinopyranosyl- $(1 \rightarrow 2)-O-\alpha$-Lrhamnopyranoside (Bp1) and the treatment with $B$. pinnatum extract showed gastroprotective and anti-ulcer activity, respectively. In addition to reduced macroscopic damage and reorganization of the mucosal structure by histopathological analysis, these potential pharmacological effects were evidenced by increasing the antioxidant defense system and modulating inflammatory markers (Table 5).

\section{DISCUSSION}

In this study, it was observed that treatment with $B$. pinnatum leaf extract could promote gastric healing of chronic ulcers in the gastric tissue of rats induced by $80 \%$ acetic acid. In addition to healing the lesion area, treatment with this species could also improve the inflammatory and oxidative stress markers evaluated. It was also observed that the pretreatment with quercetin $3-O-\alpha-\mathrm{L}$-arabinopyranosyl- $(1 \rightarrow 2)$ $O-\alpha$-L-rhamnopyranoside (Bp1) protected the gastric mucosa of mice against acute lesions caused by ethanol and indomethacin, thus suggesting that this flavonoid had a potential gastroprotective effect. In addition to reducing the lesion area, the pretreatment with this flavonoid significantly improved the oxidative stress and inflammation parameters in the gastric tissue.

The chronic gastric ulcer caused by acetic acid instillation was similar to human ulcers because they develop in the same location and showed an equal degree of severity and chronicity, as well as in the healing process of the affected 
area (Okabe et al., 2005). The development of ulcers by acetic acid induction occurs due to changes in different factors such as PG production, growth factor, NO, cytokine contents, and mucus production (Tarnawsk, 2005; Kang et al., 2014). The healing of chronic ulcers is a complex process which involves cell migration, proliferation, and replication of epithelial cells near the margins to restore the glandular architecture and granulation tissue angiogenesis at the base of the ulcer (Tarnawsk, 2005; Kang et al., 2014). Corroborating the hypothesis that the $B$. pinnatum leaf extract could stimulate gastric healing, the ulcerated area provoked by acetic acid was significantly reduced by the treatment with this species in a dose-dependent manner. It is possible to note a reduction in the ulcerated area by macroscopic analysis (Figures $3 \mathbf{E}, \mathbf{F}$ ) and by histological analysis (Figures $\mathbf{8 E}, \mathbf{F}$ ) of the lesion of the $B$. pinnatum extract-treated group at doses of 250 and $500 \mathrm{mg} / \mathrm{kg}$. In Figures 3B, 8B, it is possible to observe extensive erosive lesions in the mucous layer and in deeper layers of the gastric wall in the ulcerated control group. In addition, reorganization of the epithelium with healing of the ulcerated area can also be observed macroscopically and histologically in the lansoprazole -treated group at a dose of $30 \mathrm{mg} / \mathrm{kg}$ (Figures 3C, 8C).

Quercetin 3-O- $\alpha$-L-arabinopyranosyl- $(1 \rightarrow 2)-O-\alpha-$ L-rhamnopyranoside (Bp1) is considered the major compound and the marker for B. pinnatum (Nascimento et al., 2018; Fernandes et al., 2021) therefore, experiments with $\mathrm{Bp} 1$ in gastric lesions induced by ethanol and indomethacin were conducted in order to assess whether the effect of the extract was related to the presence of this compound. The induction of acute gastric lesions by ethanol and indomethacin could cause intense damage to the gastric tissue in the form of ulcerative lesions in the mucosa layer (Tu et al., 2017; Czekaj et al., 2018; Kangwan et al., 2019; Ugwah et al., 2019).

Ethanol induces acute gastric lesions by increasing lipid peroxidation and oxidative stress (Czekaj et al., 2018), which consequently leads to developing injuries in the mucosa layer with increasing MDA, inflammatory cytokine, and NO production levels, as well as an increase in the MPO enzyme activity. Ethanol decreases the PGE2 and antioxidant enzyme activity levels, reduces the secretion of bicarbonate and mucus generation, in addition to producing excessive (reactive oxygen species) ROS, disturbs the gastric microcirculation, and provokes lesions on the epithelial cells, causing a rupture in mucous cell membranes and cytotoxic effects (Tu et al., 2017).

Oral administration of indomethacin can cause serious macroscopic damage to the gastric mucosa layer, such as a loss of normal color, mild hemorrhaging, moderate edema, and severe mucosal disruption. Indomethacin weakens the gastric mucosa by inhibiting synthesis of PGs by cyclooxygenase-1 (COX-1). In addition, NSAIDs also act as a prooxidant catalyst and initiate the lipoperoxidation-producing ROS, in turn interfering in the antioxidant system of endogenous cells of the mucosa, inducing leukocyte recruitment, and boosting the inflammatory response (Kangwan et al., 2019; Ugwah et al., 2019).

In this work, it was possible to note that the pretreatment with quercetin 3-O- $\alpha$-L-arabinopyranosyl- $(1 \rightarrow 2)-O-\alpha-$ L-rhamnopyranoside (Bp1) at a dose of $5 \mathrm{mg} / \mathrm{kg}$ in the ethanol- induced model (Figures 10A, 15A, respectively), while the doses of 5 and $10 \mathrm{mg} / \mathrm{kg}$ in the indomethacin-induced model (Figures 10B, $15 \mathrm{~B}$, respectively), reduced the ulcerated area by macroscopic analysis and by histological analysis. In Figures 10A, B2, 15A2, B2, it is possible to observe extensive erosive lesions in the mucous layer in the gastric lesion control group in both induced models. In addition, the reorganization of the epithelium can also be macroscopically and histologically observed in the ranitidine-treated group at a dose of $50 \mathrm{mg} / \mathrm{kg}$ (Figures 10A, B3, 15A3, B3, respectively).

The acetic acid instillation in the subserosal layer induces a state of stress in the gastric tissue, consequently inducing a chronic gastric ulcer. ROS production and oxidative stress are the major cause for developing and aggravating the ulcer. Furthermore, chronic ulcer induced by acetic acid leads to chronic oxidative stress with decreased SOD activity and GSH levels and increased lipid peroxidation (MDA) levels. It is known that SOD, GSH, and MDA play important roles in protecting the gastric mucosa against oxidative gastric mucosal injury (Kwiecien et al., 2002; Adibhatla et al., 2010).

Endogenous sulfhydryl (SH) plays an important role in maintaining the integrity of the gastric mucosa and elevating the basal concentration of nonprotein sulfhydryl, which is mostly reduced GSH ( $\gamma$-glutamyl-cysteinyl-glycine), indicating their possible implications for gastroprotection (Nagy et al., 2007). MDA is a reliable parameter of ROS-induced mucosal injury (Kwiecien et al., 2002). SOD is a group of metalloenzymes which catalyze the dismutation of superoxide radical into hydrogen peroxide and oxygen. SOD is the first line of defense inside cells against ROS (Fernández et al., 2009). Therefore, an expression analyses by SOD immunohistochemistry and detecting GSH and MDA levels can reflect and indicate oxidative stress in the tissue. Treatment with $B$. pinnatum extract at the doses of 250 and $500 \mathrm{mg} / \mathrm{kg}$ and lansoprazole at a dose of $30 \mathrm{mg} / \mathrm{kg}$ stimulated SOD expression (Figures 9C-E, respectively) and the GSH levels (Figure 4) in the gastric tissue, in addition to decreasing the MDA levels (Figure 5).

Oral administration of ethanol and indomethacin also causes a state of oxidative stress in the gastric mucosa, provoking the development of gastric lesions (Karkkainen et al., 2015; Lim et al., 2019). Pretreatment with quercetin 3-O- $\alpha$-L-arabinopyranosyl$(1 \rightarrow 2)$-O- $\alpha$-L-rhamnopyranoside $(\mathrm{Bp} 1)$ at a dose of $5 \mathrm{mg} / \mathrm{kg}$ and ranitidine at $50 \mathrm{mg} / \mathrm{kg}$ could elevate the GSH (Figures 11A,B, respectively) and decrease the MDA (Figures 12A,B, respectively) levels in the gastric mucosa. These results suggest that $B$. pinnatum leaf extract and the isolated quercetin 3-O$\alpha$-L-arabinopyranosyl-( $1 \rightarrow 2)$-O- $\alpha$-L-rhamnopyranoside (Bp1) are capable of stimulating antioxidant system remodeling in the gastric mucosa during the inflammatory process in this tissue.

MPO activity in the ulcerated gastric tissue induced by acetic acid is higher than normal gastric tissue (Keto et al., 2002). Therefore, MPO is an important indicator of inflammation in the chronic gastric model to observe extensive neutrophil infiltration/aggregation in gastric tissue in this situation (Naito et al., 1998). In this study it was observed that the treatment with B. pinnatum leaf extract at all doses and lansoprazole $30 \mathrm{mg} / \mathrm{kg}$ were capable of decreasing the MPO activity (Figure 6) and the histological analysis (Figures 8E,F) showed a decrease in the 
inflammatory infiltrate and edema with the treatment with the doses of 250 and $500 \mathrm{mg} / \mathrm{kg}$ and with lansoprazole at $30 \mathrm{mg} / \mathrm{kg}$ (Figure 8C).

Oral administration of ethanol and indomethacin can result in high neutrophil infiltration with consequent elevated MPO activity collaborating to develop gastric lesions (Hansson 2006; Raesi et al., 2019). Pretreatment with quercetin 3-O$\alpha$-L-arabinopyranosyl-( $1 \rightarrow 2)-O-\alpha$-L-rhamnopyranoside $(\mathrm{Bp} 1)$ at a dose of $5 \mathrm{mg} / \mathrm{kg}$ and with ranitidine at $50 \mathrm{mg} / \mathrm{kg}$ decreased the MPO activity in the gastric mucosa (Figures 13A,B).

Gastric inflammation around the ulcer region stimulates the migration of macrophages and polymorphonuclear cells, and this consequently leads to an increase in the release of proinflammatory cytokines and mediators form these cells. Proinflammatory cytokines such as TNF- $\alpha$ and IL- $1 \beta$ play an important role in the pathogenesis of gastric ulcer (Raeesi and Eskandari-Ro, 2019). IL-1 $\beta$ and TNF- $\alpha$ levels are elevated and IL10 levels are reduced in chronic gastric ulcer (Haghazali et al., 2011). The beneficial effect of B. pinnatum leaf extract can be seen in the modulation of cytokines, reducing the pro-inflammatory cytokines IL-1 $\beta$ and (Figure 7A) TNF- $\alpha$ levels (Figure 7B) and elevating the IL-10 levels, an important anti-inflammatory cytokine (Figure 7C).

Oral administration of ethanol and indomethacin also elevated the IL-1 $\beta$ and TNF- $\alpha$ levels and reduced the IL-10 levels. Pretreatment with quercetin 3-O- $\alpha$-L-arabinopyranosyl- $(1 \rightarrow 2)$ $O$ - $\alpha$-L-rhamnopyranoside (Bp1) at a dose of $5 \mathrm{mg} / \mathrm{kg}$ could reduce the IL-1 $\beta$ and TNF- $\alpha$ levels and elevated the IL-10 levels in the ethanol-induced model (Figures 14A,C,E, respectively). In addition, pretreatment with quercetin 3-O- $\alpha$-L-arabinopyranosyl$(1 \rightarrow 2)-O-\alpha$-L-rhamnopyranoside (Bpl) at doses of 5 and $10 \mathrm{mg} / \mathrm{kg}$ reduced the IL- $1 \beta$ and TNF- $\alpha$ levels and elevated the IL-10 levels in the gastric mucosa in the indomethacin-induced model (Figures 14B,D,F, respectively). These results associated with the histological analysis indicate that the $B$. pinnatum leaves and its major flavonoid (Bp1) were capable of modulating the inflammatory process. We hypothesize that quercetin 3-O- $\alpha$-L-arabinopyranosyl$(1 \rightarrow 2)-O-\alpha$-L-rhamnopyranoside (Bp1) showed a cytoprotective effect in the gastric mucosa and that the $B$. pinnatum leaf extract promoted the healing process in this tissue.

TNF- $\alpha$ and other pro-inflammatory cytokines activate NF- $\kappa B$, and this action stimulates the activation of inducible enzyme isoforms of the inflammatory process such as COX-2. COX-2 is upregulated during the inflammatory process, and this results in an elevated production of pro-inflammatory PGs (Karin et al., 2002; Virginia et al., 2005; Gloire et al., 2006; Kang et al., 2014). Immunohistochemical analysis showed that the treatment with $B$. pinnatum extract at doses of 250 and $500 \mathrm{mg} / \mathrm{kg}$ and with lansoprazole $(30 \mathrm{mg} / \mathrm{kg})$ could decrease NF-kB (Figures $\mathbf{9 M - O}$, respectively) and COX-2 (Figures $\mathbf{9 H}-\mathbf{J}$, respectively) expressions in the gastric tissue in the chronic ulcer model.

ROS are considered as the second messenger to initiate redoxsensitive signal transduction pathway with mitogen-activated protein kinase cascade and is related to NF- $\kappa \mathrm{B}$ transcription, acting to control the gene expression of several proinflammatory mediators and provoking inflammatory damage in gastric tissue (Kang and Kim, 2017). ROS also simultaneously stimulates the inhibitor kappa B (IкB) kinase which induces proteasomal breakdown of IкBa and activates NF- $\kappa \mathrm{B}$. NF- $\kappa \mathrm{B}$ is a transcription factor which promotes target genes and triggers transcription of inflammatory cytokines and chemokines when linking to $\kappa-\beta$. The NF- $\kappa B$ family of transcription factors show an important role in inflammation (Dambrova et al., 2010). Therefore, inhibiting NF- $\kappa \mathrm{B}$ activation may be an effective way to prevent and treat gastric ulcer.

The present study showed that three flavonoids-quercetin 3-O- $\alpha$-L-arabinopyranosyl- $(1 \rightarrow 2)$-O- $\alpha$-L-rhamnopyranoside (Bp1), kaempferol 3-O- $\alpha$-L-arabinopyranosyl-( $1 \rightarrow 2)-O-\alpha-$ L-rhamnopyranoside (Bp2), and quercetin 3-O-a-Lrhamnopyranoside (Bp3)-were quantified in B. pinnatum extract, with BP1 being the major compound and the possible active marker. These findings are important for quality control of the raw material obtained from this plant.

Flavonoids are a group of phenolic compounds found in different plant species (Glevitzky et al., 2019). The basic structure of flavonoids consists of 15 carbon atoms, arranged in the form C5-C3-C6 (aryl-propyl-aryl), which corresponds to two aromatic rings linked by a unit of three carbon atoms (Justino, 2017). This class of compounds can act as antioxidants by free radical scavenging mechanism (Dangles et al., 2000), and this can be explained due to a lack of -OH groups on the B-ring (Amic et al. 2003).

It is described in the literature that flavonoids have pharmacological activities, for example, this class can inhibit the proliferation of inflammatory cells and consequently suppress the expressions of inflammatory cytokines. In addition, they can also decrease ROS with a decrease in NO concentration and increase in endogen oxidative enzyme levels (Antonisamy et al., 2016; Wang et al., 2017). Therefore, the results obtained from this study corroborate with previous studies and suggest that the quercetin $3-O-\alpha-L-a r a b i n o p y r a n o s y l-(1 \rightarrow 2)-O-\alpha-$ L-rhamnopyranoside (Bp1) flavonoid isolated from the $B$. pinnatum species may be one of the constituents responsible for the anti-ulcer activity of this species.

Nowadays, the bioactivity of isolated phenolics and phenolicrich extracts focusing on suppression of chronic diseases has been widely discussed in the literature due to their protective effect in inflammatory diseases with a remarkable capacity because of their multiple inhibitory activities of proinflammatory mediators. Phenolic compounds can be found in many foods and medicinal plants; therefore, researchers have proposed that dietary sources rich in phenolic compounds and/or herbal medicines can be an alternative in treating inflammation and related diseases, with minimal or null adverse side effects or in a more natural, drugfree fashion (Ambriz-Pérez et al., 2016; Shahidi and Yeo, 2018; de Moraes et al., 2020). In this perspective, B. pinnatum leaf extract can be a new source of raw material which is rich in phenolics to be applied as food or medicine.

However, in a previous study by Araújo et al. (2018), it was observed that the pretreatment with $B$. pinnatum leaf extract against acute gastric lesions models showed a higher inhibition percentage of gastric lesions when only compared with the pretreatment with the isolated flavonoid used in this study. In addition, the treatment with B. pinnatum leaf extract against chronic ulcer gastric model carried out in this study also showed a higher inhibition percentage when 
compared to pretreatment with the isolated flavonoid. This might suggest that because $B$. pinnatum leaf extract is a complex vegetable matrix and has other substances in its composition, it has better antiulcer activity than administering the isolated flavonoid. We hypothesize that the other compounds present in it can act synergistically, potentiating the anti-inflammatory effect and consequently the anti-ulcer property of this species. However, we can suggest that future studies should be carried out with this extract and other isolated compounds present in it, such as pharmacokinetic and pharmacodynamic studies, such that more scientific evidence will be generated to confirm or refute this hypothesis.

\section{CONCLUSION}

Pretreatment with quercetin 3-O- $\alpha$-L-arabinopyranosyl- $(1 \rightarrow 2)-O-\alpha-$ L-rhamnopyranoside $(\mathrm{Bp} 1)$ and treatment with $B$. pinnatum extract exhibited relevant pharmacological effects in preclinical assays from showing significant gastroprotective and anti-ulcer activities, respectively. These effects were mainly observed through increasing the antioxidant defense system and modulating inflammatory markers. Overall, this work can collaborate to develop a new phytotherapeutic treatment of peptic ulcer disease or as a new source of raw material as a functional food ingredient to be incorporated into food matrices.

\section{DATA AVAILABILITY STATEMENT}

The original contributions presented in the study are included in the article/Supplementary Material; further inquiries can be directed to the corresponding author.

\section{REFERENCES}

Adibhatla, R. M., and Hatcher, J. F. (2010). Lipid Oxidation and Peroxidation in CNS Health and Disease: from Molecular Mechanisms to Therapeutic Opportunities. Antioxid. Redox Signal. 12, 125125e169-69. doi:10.1089/ ars.2009.2668

Afzal, M., Gupta, G., Kazmi, I., Rahman, M., Afzal, O., Alam, J., et al. (2012). Antiinflammatory and Analgesic Potential of a Novel Steroidal Derivative from Bryophyllum Pinnatum. Fitoterapia 83, 853-858. doi:10.1016/j.fitote.2012.03.013

Allorge-Boiteau, L. (1996). "Madagascar centre de speciation et d'origine du genre Kalanchoe (Crassulaceae)," in Biogéographie de Madagascar. Editor W.R. Lourenc, o (Paris: ORSTOM), 137-145.

Amang, A. P., Mezui, C., Siwe, G. T., Emakoua, J., Mbah, G., Nkwengoua, E. Z., et al. (2017). Healing and Antisecretory Effects of Aqueous Extract of Eremomastax Speciosa (Acanthaceae) on Unhealed Gastric Ulcers. Biomed. Res. Int. 2017, 1924320. doi:10.1155/2017/1924320

Amaral, A. C. F., Simões, E. V., and Ferreira, J. L. P. (2005). Coletânea científica de plantas de uso medicinal. Curitiba: Fiocruz.

Ambriz-Prez, D. L., Leyva-Lpez, N., Gutierrez-Grijalva, E. P., and Heredia, J. B. (2016). Phenolic Compounds: Natural Alternative in Inflammation Treatment. A Review. Cogent Food Agric. 2 (1), 1131412. doi:10.1080/ 23311932.2015.1131412

Amic, D., Davidovic-Amic, D., Beslo, D., and Trinajstic, N. (2003). StructureRadical Scavenging Activity Relationships of Flavonoids. Croat. Chem. Acta 76 (1), 55 .

\section{ETHICS STATEMENT}

The animal study was approved by the Ethics Committee of Laboratory Animals of the Federal University of Rio Grande do Norte (CEUA no. 029.047/2017).

\section{AUTHOR CONTRIBUTIONS}

EA, AWA, and JF performed the investigation and analyzed data. GG and SZ conceived and designed the experimental tests. VS, ET, AAA, and RAJ contributed reagents/materials/analysis. The paper was written and reviewed by EA, GG, and SZ.

\section{FUNDING}

This study was financed by the Coordenação de Aperfeiçoamento de Pessoal de Nível Superior-Brasil (CAPES). EA is a predoctoral fellow from Federal University of Rio Grande do Norte-UFRN ("Programa de Pós-graduação em Ciências da Saúde"). RJ received funding from Productivity Scholarship CNPq 301877/2019 (Brazil) and funding from the European Union's Horizon 2020 research and innovation programme under grant agreement 872391 (CONCRETE). SZ is a research productivity fellow of the CNPq (Grant number 313727/2020-1).

\section{ACKNOWLEDGMENTS}

The authors acknowledge CAPES and Postgraduate Program in Health Science, UFRN, Brazil, for experimental support.

Andrade, A. W. L., Guerra, G. C. B., de Souza Araújo, D. F., de Araújo Júnior, R. F., de Araújo, A. A., de Carvalho, T. G., et al. (2020). Anti-Inflammatory and Chemopreventive Effects of Bryophyllum Pinnatum (Lamarck) Leaf Extract in Experimental Colitis Models in Rodents. Front. Pharmacol. 11, 998. doi:10.3389/fphar.2020.00998

Antonisamy, P., Subash-Babu, P., Albert-Baskar, A., Alshatwi, A. A., Aravinthan, A., Ignacimuthu, S., et al. (2016). Experimental Study on Gastroprotective Efficacy and Mechanisms of Luteolin-7-O-Glucoside Isolated from Ophiorrhiza mungos Linn. In Different Experimental Models. J. Funct. Foods 25, 302-313. doi:10.1016/j.jff.2016.06.003

Aparicio, R., and Harwood, J. (2013). in Handbook of Olive Oil. Editors R. Aparicio and J. Harwood (Boston, MA: Springer US). doi:10.1007/978$1-4614-7777-8$

Araújo, M. B., Borini, P., and Guimarães, R. C. (20142014). Etiopathogenesis of Peptic Ulcer: Back to the Past? Arq. Gastroenterol. 51, 155-161. doi:10.1590/ S0004-28032014000200016

de Araújo, E., Guerra, G., Araújo, D., de Araújo, A., Fernandes, J., de Araújo Júnior, R., et al. (2018). Gastroprotective and Antioxidant Activity of Kalanchoe Brasiliensis and Kalanchoe Pinnata Leaf Juices against Indomethacin and Ethanol-Induced Gastric Lesions in Rats. Ijms 19, 1265. doi:10.3390/ ijms 19051265

de Araújo, R. F., Reinaldo, M. P., Brito, G. A., Cavalcanti, Pde. F., Freire, M. A., de Moura Freire, M. A., et al. (2014). Olmesartan Decreased Levels of IL- $1 \beta$ and TNF- $\alpha$, Down-Regulated MMP-2, MMP-9, COX-2, RANK/RANKL and UpRegulated SOCs-1 in an Intestinal Mucositis Model. PLoS ONE 9, e114923. doi:10.1371/journal.pone.0114923 
Bhutada, P., Mundhada, Y., Bansod, K., Bhutada, C., Tawari, S., Dixit, P., et al. (2010). Ameliorative Effect of Quercetin on Memory Dysfunction in Streptozotocin-Induced Diabetic Rats. Neurobiol. Learn. Mem. 94, 293-302. doi:10.1016/j.nlm.2010.06.008

Brazil (2017). Agência Nacional de Vigilância Sanitária (ANVISA), Resolução da Diretoria Colegiada-RDC No 166, de 24 de julho de 2017. Dispõe sobre a validação de métodos analiticose daoutras providências. Available at: https://20. anvisa.gov.br/coifa/pdf/rdc166.pdf).

Bungãu, S. G., and Popa, V. C. (2015). Between Religion and Science: Some Aspects: Concerning Illness and Healing in Antiquity. Transylv. Rev. 26 (3), 3-19.

Cardona, F., Andrés-Lacueva, C., Tulipani, S., Tinahones, F. J., and QueipoOrtuño, M. I. (2013). Benefits of Polyphenols on Gut Microbiota and Implications in Human Health. J. Nutr. Biochem. 24 (24), 1415-1422. doi:10.1016/j.jnutbio.2013.05.001

Czekaj, R., Majka, J., Magierowska, K., Sliwowski, Z., Magierowski, M., Pajdo, R., et al. (2018). Mechanisms of Curcumin-Induced Gastroprotection against Ethanol-Induced Gastric Mucosal Lesions. J. Gastroenterol. 53, 618-630. doi:10.1007/s00535-017-1385-3

Dambrova, M., Zvejniece, L., Skapare, E., Vilskersts, R., Svalbe, B., Baumane, L., et al. (2010). The Anti-inflammatory and Antinociceptive Effects of NF-kappaB Inhibitory Guanidine Derivative ME10092. Int. Immunopharmacol. 10 (4), 455-460. doi:10.1016/j.intimp.2010.01.006

Dangles, O., Fargeix, G., and Dufour, C. (2000). Antioxidant Properties of Anthocyanins and Tannins: a Mechanistic Investigation with Catechin and the $3^{\prime}, 4^{\prime}, 7$-trihydroxyflavylium Ion. J. Chem. Soc. Perkin Trans. 22, 1653-1663. doi:10.1039/B003260N

De Moraes, F. P., Xiong, J., Borges, K. C., Hoskin, R. T., and Esposito, D. (2020). Phytochemical Content, Antioxidant, Anti-inflammatory Activities and Wound Healing Properties of Freeze-Dried Fruits. Act. Sci. Nutr. Health 4 (1), 63-71. doi:10.31080/ASNH.2020.04.0576

Dokmeci, D., Akpolat, M., Aydogdu, N., Doganay, L., and Turan, F. N. (2005). L-carnitine Inhibits Ethanol-Induced Gastric Mucosal Injury in Rats. Pharmacol. Rep. 57, 481-488.

Dos Santos Nascimento, L. B., de Aguiar, P. F., Leal-Costa, M. V., Coutinho, M. A. S., Borsodi, M. P. G., Rossi-Bergmann, B., et al. (2018). Optimization of Aqueous Extraction from Kalanchoe Pinnata Leaves to Obtain the Highest Content of an Anti-inflammatory Flavonoid Using a Response Surface Model. Phytochem. Anal. 29, 308-315. doi:10.1002/pca.2744

Esterbauer, H., and Cheeseman, K. H. (1990). Determination of Aldehydic Lipid Peroxidation Products: Malonaldehyde and 4-hydroxynonenal. Methods Enzymol. 186, 407-421. doi:10.1016/0076-6879(90)86134-h

Etxeberria, U., Arias, N., Boqué, N., Macarulla, M. T., Portillo, M. P., Martínez, J. A., et al. (2015). Reshaping Faecal Gut Microbiota Composition by the Intake of Trans-resveratrol and Quercetin in High-Fat Sucrose Diet-Fed Rats. J. Nutr. Biochem. 26, 651-660. doi:10.1016/j.jnutbio. 2015.01.002

Farzaei, M. H., Abdollahi, M., and Rahimi, R. (2015). Role of Dietary Polyphenols in the Management of Peptic Ulcer. World J. Gastroenterol. 21, 6499-6517. doi:10.3748/wjg.v21.i21.6499

Fernandes, J. M., Félix-Silva, J., da Cunha, L. M., Gomes, J. A., Siqueira, E. M., Gimenes, L. P., et al. (2016). Inhibitory Effects of Hydroethanolic Leaf Extracts of Kalanchoe Brasiliensis and Kalanchoe Pinnata (Crassulaceae) against Local Effects Induced by Bothrops jararaca Snake Venom. Plos One 11, e0168658. doi:10.1371/journal.pone.0168658

Fernandes, J. M., Cunha, L. M., Azevedo, E. P., Lourenço, E. M. G., FernandesPedrosa, M. F., and Zucolotto, S. M. (2019). Kalanchoe Laciniata and Bryophyllum Pinnatum: an Updated Review about Ethnopharmacology, Phytochemistry, Pharmacology and Toxicology. Revista Brasileira de Farmacognosia 29, 529-558. doi:10.1016/j.bjp.2019.01.012

Fernández, C., San Miguel, E., and Fernández-briera, A. (2009). Superoxide Dismutase and Catalase: Tissue Activities and Relation with Age in the Long-Lived Species Margaritifera Margaritifera. Biol. Res. 42, 57-68. doi:10.4067/S0716-97602009000100006

Ferreira, R. T., Coutinho, M. A. S., Malvar, D. d. C., Costa, E. A., Florentino, I. F., Costa, S. S., et al. (2014). Mechanisms Underlying the Antinociceptive, Antiedematogenic, and Anti-inflammatory Activity of the Main Flavonoid
fromKalanchoe Pinnata. Evidence-Based Complement. Altern. Med. 2014, 1-8. doi:10.1155/2014/429256

Gehrig, H., Gaußmann, O., Marx, H., Schwarzott, D., and Kluge, M. (2001). Molecular Phylogeny of the Genus Kalanchoe (Crassulaceae) Inferred from Nucleotide Sequences of the ITS-1 and ITS-2 Regions. Plant Sci. 160, 827-835. doi:10.1016/s0168-9452(00)00447-7

Glevitzky, I., Dumitrel, G. A., Glevitzky, M., Pasca, B., Otrisal, P., BungauCioca, S., et al. (2019). Statistical Analysis of the Relationship between Antioxidant Activity and the Structure of Flavonoid Compounds. Rev. Chim. 70 (9), 3103-3107. doi:10.37358/RC.19.9.7497

Gloire, G., Legrand-Poels, S., and Piette, J. (2006). NF-kappaB Activation by Reactive Oxygen Species: Fifteen Years Later. Biochem. Pharmacol. 72 (11)-505. doi:10.1016/j.bcp.2006.04.011

Graham, D. Y. (20142014). History of Helicobacter pylori, Duodenal Ulcer, Gastric Ulcer and Gastric Cancer. World J. Gastroenterol. 20, 5191-5204. doi:10.3748/ wjg.v20.i18.5191

Haghazali, M., Molaei, M., Mashayekhi, R., Zojaji, H., Pourhoseingholi, M. A., Shooshtarizadeh, T., et al. (2011). Proinflammatory Cytokines and Thrombomodulin in Patients with Peptic Ulcer Disease and Gastric Cancer, Infected with Helicobacter pylori. Indian J. Pathol. Microbiol. 54, $103 \mathrm{e} 106$. doi:10.4103/0377-4929.77343

Hansson, M., Olsson, I., and Nauseef, W. M. (2006). Biosynthesis, Processing, and Sorting of Human Myeloperoxidase. Arch. Biochem. Biophys. 445, 214-224. doi:10.1016/j.abb.2005.08.009

Havens, J. M., Castillo-Angeles, M., Nitzschke, S. L., and Salim, A. (2018). Disparities in Peptic Ulcer Disease: A Nationwide Study. Am. J. Surg. 216 (6), 1127-1128. doi:10.1016/j.amjsurg.2018.08.025

Herrera, A. (20082008). Crassulacean Acid Metabolism and Fitness under Water Deficit Stress: if Not for Carbon Gain, what Is Facultative CAM Good for? Ann. Bot. V 103, 645-653. doi:10.1093/aob/mcn145

Hollander, D., and Tarnawski, A. (1986). Dietary Essential Fatty Acids and the Decline in Peptic Ulcer Disease-Aa Hypothesis. Gut 27, 239-242. doi:10.1136/gut.27.3.239

ICH (2005). Q2 (R1), International Conference on Harmonisation of Technical Requirements for Registration of Pharmaceuticals for Human Use (ICH), Validation of Analytical Procedures: Text and Methodology, ICH Harmonised Tripartite Guideline. Available at: https:/ema.europa.eu/en/ichq2-r1 validation-analytical-procedures-text-methodology\#current-effective versionsection (Accessed April 12, 2021).

Justino, J. (2017). Flavonoids - from Biosynthesis to Human Health. Intech Open 4. (Accessed September 20, 2021). doi:10.5772/67810

Kakub, G., and Gulfraz, M. (2007). Cytoprotective Effects of Bergenia Ciliata Sternb, Extract on Gastric Ulcer in Rats. Phytother. Res. 21, 1217-1220. doi:10.1002/ptr.2242

Kang, G. D., and Kim, D. H. (2017). Ponciretin Attenuates Ethanol-Induced Gastric Damage in Mice by Inhibiting Inflammatory Responses. Int. Immunopharmacol. 43, 179-186. doi:10.1016/j.intimp.2016.12.021

Kang, J. W., Yun, N., Han, H. J., Kim, J. Y., Kim, J. Y., and Lee, S. M. (20142014). Protective Effect of Flos Lonicerae against Experimental Gastric Ulcers in Rats: Mechanisms of Antioxidant and Antiinflammatory Action. Evid. Based. Complement. Alternat. Med. 2014, 596920. doi:10.1155/2014/596920

Kangwan, N., Pintha, K., Lekawanvijit, S., and Suttajit, M. (2019). Rosmarinic Acid Enriched Fraction from Perilla Frutescens Leaves Strongly Protects Indomethacin-Induced Gastric Ulcer in Rats. Biomed. Res. Int. 2019, 9514703. doi:10.1155/2019/9514703

Kärkkäinen, J. M., Miilunpohja, S., Rantanen, T., Koskela, J. M., Jyrkkä, J., Hartikainen, J., et al. (2015). Alcohol Abuse Increases Rebleeding Risk and Mortality in Patients with Non-variceal Upper Gastrointestinal Bleeding. Dig. Dis. Sci. 60, 3707-3715. doi:10.1007/s10620-015-3806-6

Keto, Y., Ebata, M., Tomita, K., and Okabe, S. (2002). Influence of Helicobacter pylori Infection on Healing and Relapse of Acetic Acid Ulcers in Mongolian Gerbils. Dig. Dis. Sci. 47 (4), 837-849. doi:10.1023/a:1014760504955

Krawisz, J. E., Sharon, P., and Stenson, W. F. (1984). Quantitative Assay for Acute Intestinal Inflammation Based on Myeloperoxidase Activity. Assessment of Inflammation in Rat and Hamster Models. Gastroenterology 87, 1344-1350. doi:10.1016/0016-5085(84)90202-6 
Kumari, A., Yadav, S. K., Pakade, Y. B., Singh, B., and Yadav, S. C. (20102010). Development of Biodegradable Nanoparticles for Delivery of Quercetin. Colloids Surf. B Biointerfaces 80, 184-192. doi:10.1016/ j.colsurfb.2010.06.002

Kuna, L., Jakab, J., Smolic, R., Raguz-Lucic, N., Vcev, A., and Smolic, M. (2019). Peptic Ulcer Disease: a Brief Review of Conventional Therapy and Herbal Treatment Options. J. Clin. Med. 8 (2), 179. doi:10.3390/ jcm8020179

Kwiecień, S., Brzozowski, T., Konturek, P. Ch., and Konturek, S. J. (20022002). The Role of Reactive Oxygen Species in Action of Nitric Oxide-Donors on StressInduced Gastric Mucosal Lesions. J. Physiol. Pharmacol. 53 (2), 761-773.

Lim, J. M., Song, C. H., Park, S. J., Park, D. C., Jung, G. W., Cho, H. R., et al. (2019). Protective Effects of Triple Fermented Barley Extract (FBe) on IndomethacinInduced Gastric Mucosal Damage in Rats. BMC Complement. Altern. Med. 19, 149. doi:10.1186/s12906-019-2457-0

Magistretti, J., Brevi, S., and de Curtis, M. (1998). The Antiulcer Activity of Treculia Acuminate Extract against Ethanol Induced Gastric Ulcer in Rats. J. Clin. Exp. Pharmacol. 41, 34-41. doi:10.1016/j.jep.2014.09.012

M. Asali, A., Alghamdi, M. A., Fallatah, S. A., Alholaily, W. A., Aldandan, R. G., Alnosair, A. H., et al. (2018). Risk Factors Leading to Peptic Ulcer Disease: Systematic Review in Literature. Int. J. Community Med. Public Health 5, 4617-4624. doi:10.18203/2394-6040.ijcmph20183869

Morais Fernandes, J., Ortiz, S., Padilha M Tavares, R., Mandova, T., Rodrigues D Araújo, E., L Andrade, A. W., et al. (2021). Bryophyllum Pinnatum Markers: CPC Isolation, Simultaneous Quantification by a Validated UPLC-DAD Method and Biological Evaluations. J. Pharm. Biomed. Anal. 193, 113682. doi:10.1016/j.jpba.2020.113682

Motilva, V., Alarcón de la Lastra, C., Bruseghini, L., Manuel Herrerias, J., and Sánchez-Fidalgo, S. (2005). COX Expression and PGE2 and PGD2 Production in Experimental Acute and Chronic Gastric Lesions. Int. Immunopharmacology 5 (2), 369-379. doi:10.1016/j.intimp.2004.10.005

Muzitano, M. F., Cruz, E. A., de Almeida, A. P., Da Silva, S. A., Kaiser, C. R., Guette, C., et al. (2006). Quercitrin: an Antileishmanial Flavonoid Glycoside from Kalanchoe Pinnata. Planta Med. 72, 81-83. doi:10.1055/s-2005-873183

Nagy, L., Nagata, M., and Szabo, S. (2007). Protein and Non-protein Sulfhydryls and Disulfides in Gastric Mucosa and Liver after Gastrotoxic Chemicals and Sucralfate: Possible New Targets of Pharmacologic Agents. World J. Gastroenterol. 13, 2053-2060. doi:10.3748/wjg.v13.i14.2053

Naito, Y., Yoshikawa, T., Matsuyama, K., Yagi, N., Arai, M., Nakamura, Y., et al. (1998). Neutrophils, Lipid Peroxidation, and Nitric Oxide in Gastric Reperfusion Injury in Rats. Free Radic. Biol. Med. 24, 494-502. doi:10.1016/ S0891-5849(97)00323-7

Okabe, S., and Amagase, K. (2005). An Overview of Acetic Acid Ulcer Models-Tthe History and State of the Art of Peptic Ulcer Research. Biol. Pharm. Bull. 28, 1321-1341. doi:10.1248/bpb.28.1321

Raeesi, M., Eskandari-Roozbahani, N., and Shomali, T. (2019). Gastroprotective Effect of Biebersteinia Multifida Root Hydro-Methanolic Extract in Rats with Ethanol-Induced Peptic Ulcer. Avicenna J. Phytomed 9 (5), 410-418.

Russo, M., Spagnuolo, C., Tedesco, I., Bilotto, S., and Russo, G. L. (2012). The Flavonoid Quercetin in Disease Prevention and Therapy: Facts and Fancies. Biochem. Pharmacol. 83, 6-15. doi:10.1016/j.bcp.2011.08.010

Safieh-Garabedian, B., Poole, S., Allchorne, A., Winter, J., and Woolf, C. J. (1995). Contribution of Interleukin-1 Beta to the Inflammation-Induced Increase in Nerve Growth Factor Levels and Inflammatory Hyperalgesia. Br. J. Pharmacol. 115, 1265-1275. doi:10.1111/j.14765381.1995.tb15035.x

Scally, B., Emberson, J. R., Spata, E., Reith, C., Davies, K., Halls, H., et al. (2018). Effects of Gastroprotectant Drugs for the Prevention and Treatment of Peptic Ulcer Disease and its Complications: a Meta-Analysis of Randomised Trials. Lancet Gastroenterol. Hepatol. 3 (4), 231-241. doi:10.1016/S2468-1253(18) $30037-2$
Shahidi, F., and Yeo, J. (2018). Bioactivities of Phenolics by Focusing on Suppression of Chronic Diseases: A Review. Int. J. Mol. Sci. 19, 1573. doi:10.3390/ijms19061573

Tarnawski, A. S. (20052005). Cellular and Molecular Mechanisms of Gastrointestinal Ulcer Healing. Dig. Dis. Sci. 50 Suppl 1, S24-S33. doi:10.1007/s10620-005-2803-6

The Plant List (20102010). The Plant List. Version 1. Published on the Internet http://www.theplantlist.org/(accessed January, 2021).

Tu, P. S., Tung, Y. T., Lee, W. T., and Yen, G. C. (2017). Protective Effect of Camellia Oil (Camellia Oleifera Abel.) against Ethanol-Induced Acute Oxidative Injury of the Gastric Mucosa in Mice. J. Agric. Food Chem. 65, 4932-4941. doi:10.1021/acs.jafc.7b01135

Ugwah, M. O., Ugwah-Oguejiofor, C. J., Etuk, E. U., Bello, S. O., and Aliero, A. A. (201911193). Evaluation of the Antiulcer Activity of the Aqueous Stem Bark Extract of Balanites Aegyptiaca L Delile in Wistar Rats. J. Ethnopharmacol. 239 (1), 111931. doi:10.1016/j.jep.2019.111931

USP (2003). United States Pharmacopeia and National Formulary (USP 26-NF 21) (Rockville, MD: United States Pharmacopeial Convention). Available at: https://newhope.com/supply-news-amp-analysis/2003-edition-united-states pharmacopeia-and-national-formulary-usp-nf-avail (Accessed April 12, 2021).

Wang, X. X., Liu, G. Y., Yang, Y. F., Wu, X. W., Xu, W., and Yang, X. W. (2017). Intestinal Absorption of Triterpenoids and Flavonoids from Glycyrrhizae radix et rhizoma in the Human Caco-2 Monolayer Cell Model. Molecules 22 (10), 1627. doi:10.3390/molecules22101627

Wang, X. Y., Yin, J. Y., Zhao, M. M., Liu, S. Y., Nie, S. P., and Xie, M. Y. (2018). Gastroprotective Activity of Polysaccharide from Hericium erinaceus against Ethanol-Induced Gastric Mucosal Lesion and Pylorus Ligation-Induced Gastric Ulcer, and its Antioxidant Activities. Carbohydr. Polym. 186 (1), 100-109. doi:10.1016/j.carbpol.2018.01.004

Weltermann, T., Schulz, C., and Macke, L. (2021). Effect of Frequently Prescribed Drugs on Gastric Cancer Risk. Best Pract. Res. Clin. Gastroenterol. 50-51, 101741. doi:10.1016/j.bpg.2021.101741

Wu, L. X., Guo, C. X., Chen, W. Q., Yu, J., Qu, Q., Chen, Y., et al. (2012). Inhibition of the Organic Anion-Transporting Polypeptide 1B1 by Quercetin: an In Vitro and In Vivo Assessment. Br. J. Clin. Pharmacol. 73, 750-757. doi:10.1111/ j.1365-2125.2011.04150.x

Youn, S. H., Lim, H., Ju, Y., Soh, J. S., Park, J. W., Kang, H. S., et al. (2018). Effect of Gastroprotective Agents on Upper Gastrointestinal Bleeding in Patients Receiving Direct Oral Anticoagulants. Scand. J. Gastroenterol. 53 (12), 1490-1495. doi:10.1080/00365521.2018.1541478

Zappi, D. (2015). Crassulaceae in Lista de Espécies da Flora do Brasil. Rio de Janeiro, Brazil: Jardim Botânico do Rio de Janeiro. Available at: http://floradobrasil.jbrj. gov.br/jabot/floradobrasil/FB22581. (Accessed February 17, 2021).

Conflict of Interest: Author RAJ was employed by company Percuros B.V.

The remaining authors declare that the research was conducted in the absence of any commercial or financial relationships that could be construed as a potential conflict of interest.

Publisher's Note: All claims expressed in this article are solely those of the authors and do not necessarily represent those of their affiliated organizations, or those of the publisher the editors and the reviewers. Any product that may be evaluated in this article, or claim that may be made by its manufacturer, is not guaranteed or endorsed by the publisher.

Copyright $\odot 2021$ De Araújo, Guerra, Andrade, Fernandes, Da Silva, De Aragão Tavares, De Araújo, de Araújo Júnior and Zucolotto. This is an open-access article distributed under the terms of the Creative Commons Attribution License (CC BY). The use, distribution or reproduction in other forums is permitted, provided the original author(s) and the copyright owner(s) are credited and that the original publication in this journal is cited, in accordance with accepted academic practice. No use, distribution or reproduction is permitted which does not comply with these terms. 